\title{
An analytical expression for the J2-integral of an interfacial crack in orthotropic bimaterials
}

DOI:

10.1111/ffe. 12587

\section{Document Version}

Accepted author manuscript

Link to publication record in Manchester Research Explorer

\section{Citation for published version (APA):}

Tafreshi, A. (2017). An analytical expression for the J2-integral of an interfacial crack in orthotropic bimaterials. Fatigue \& Fracture of Engineering Materials and Structures , 40(9), 1443-1458. https://doi.org/10.1111/ffe.12587

\section{Published in:}

Fatigue \& Fracture of Engineering Materials and Structures

\section{Citing this paper}

Please note that where the full-text provided on Manchester Research Explorer is the Author Accepted Manuscript or Proof version this may differ from the final Published version. If citing, it is advised that you check and use the publisher's definitive version.

\section{General rights}

Copyright and moral rights for the publications made accessible in the Research Explorer are retained by the authors and/or other copyright owners and it is a condition of accessing publications that users recognise and abide by the legal requirements associated with these rights.

\section{Takedown policy}

If you believe that this document breaches copyright please refer to the University of Manchester's Takedown Procedures [http://man.ac.uk/04Y6Bo] or contact uml.scholarlycommunications@manchester.ac.uk providing relevant details, so we can investigate your claim.

\section{OPEN ACCESS}




\section{An analytical expression for the $\mathbf{J}_{2}$-integral of an interfacial crack in orthotropic bimaterials}

A Tafreshi

orcid.org/0000-0001-6065-7459

\section{School of Mechanical, Aerospace and Civil Engineering \\ University of Manchester, M13 9PL \\ atafreshi@manchester.ac.uk}

This paper presents a new analytical expression relating the $\mathrm{J}_{2}$-integral and stress intensity factors(SIF) in an in-plane traction free crack between two orthotropic elastic solids using the complex function method. The singular oscillatory near tip field of a bimaterial interfacial crack is usually characterized by a pair of SIFs. In linear elastic interfacial fracture mechanics, the majority of numerical and experimental methods rely on the analytical equations relating $\mathrm{J}_{\mathrm{k}^{-}}$ integrals and SIFs. Although an analytical equation relating $\mathrm{J}_{1}$-integral or strain energy release rate and SIFs is available, a similar relation for $\mathrm{J}_{2}$-integral in debonded anisotropic solids is non-existent. Using this new analytical expression, in conjunction with the values of $J_{k}$, the SIFs can be computed without the need for an auxiliary relation. An example with known analytical solutions for SIFs is presented to show the variation of the $\mathrm{J}_{2}$-integral near the crack tip of a bimaterial orthotropic plate. Different bimaterial combinations are considered and the effect of material mismatch on $J_{k}$ is demonstrated.

\section{Keywords}

Bimaterial interface crack, debonded dissimilar anisotropic materials, $J_{k}$-integral, mixed mode fracture, orthotropic materials, stress intensity factor 


\section{NOMENCLATURE}

a $=$ half crack length or crack half chord length

$a_{k}=$ local coordinates at the crack tip

$\mathrm{A}_{\mathrm{jk}}=$ complex constants

$\mathrm{B}_{\mathrm{jk}}=$ complex constants

$D_{\mathrm{j}}(\mathrm{z}) \quad=$ comlex functions

$\mathrm{d}_{\mathrm{jk}}(\mathrm{z})=$ complex functions

$\mathrm{E}_{\mathrm{j}} \quad=$ modulus of elasticity in the $\mathrm{x}_{\mathrm{j}}$ direction

$\mathrm{f}_{\mathrm{j}}(\mathrm{z}) \quad=$ complex functions

$g(z)=$ complex vector $g(z)=B\left[\begin{array}{l}f_{1}(z) \\ f_{2}(z)\end{array}\right]$

$\mathrm{G}(\mathrm{z}) \quad=\quad$ complex vector $G(z)=g^{\prime}(z)=B\left[\begin{array}{l}f_{1}^{\prime}(z) \\ f_{2}^{\prime}(z)\end{array}\right]$

$\mathrm{G}_{12}=$ Shear modulus

$\mathrm{H}_{\mathrm{jk}} \quad=\quad$ real constants

$\mathrm{i}=\sqrt{-1}$

$\mathrm{J}_{\mathrm{k}}=(\mathrm{k}=1,2), \mathrm{J}_{\mathrm{k}}$-Integrals

$\mathrm{K}_{1}, \mathrm{~K}_{2}=$ modes 1 and 2 stress intensity factors, respectively

$\mathrm{M}_{\mathrm{jk}} \quad=$ complex functions

(n) $\quad=$ material number

$n_{k}=$ direction cosines of the unit outward normal vector to the surface of the elastic body

$\mathrm{p}_{\mathrm{j}}=\operatorname{Im}\left(\mu_{j}\right)$

$\mathrm{P}_{\mathrm{jk}} \quad=$ complex constants

$\mathrm{q}_{\mathrm{j} \mathrm{k}} \quad=$ real constants

$Q_{j k}=$ real constants

$r=$ small radial distance from the crack tip

$\mathrm{s}_{\mathrm{jk}}=$ elastic compliance matrix $(\mathrm{j}, \mathrm{k}=1,2,6)$

$$
S_{11}=\frac{1}{E_{1}} \quad S_{22}=\frac{1}{E_{2}} \quad S_{66}=\frac{1}{G_{12}} \quad S_{12}=-\frac{v_{12}}{E_{1}}=-\frac{v_{21}}{E_{2}}
$$

$\mathrm{t}_{\mathrm{j}}=$ traction vector

$\mathrm{u}_{\mathrm{j}}=$ displacement vector 


$$
\begin{array}{lll}
\mathrm{x}_{\mathrm{j}} & =\text { rectangular Cartesian coordiantes } \\
\mathrm{W} & =\text { strain energy density } \\
\mathrm{Y}(z) & =\text { Complex matrix function } \\
\mathrm{z}_{\mathrm{j}} & =\text { complex coordiantes }\left(z=x_{1}+i x_{2}\right) \\
\alpha_{\mathrm{jk}} \text { and } \beta_{\mathrm{jk}} & =\text { real constant matrices } \\
\beta_{0} & =\text { bimaterial constant } \\
\Delta_{\mathrm{jk}} & =\text { Hermitian matrix }(\Delta=H+i Q) \\
\varepsilon & =\text { bimaterial constant } \\
\varepsilon_{\mathrm{jk}} & =\text { strain tensor } \\
\phi(z) & =\text { complex function } \\
\psi(z) & =\text { complex function } \\
\mu_{\mathrm{s}} & =\text { roots of the characteristic equation } \\
v_{\mathrm{jk}} & =\text { Poisson's ratio } \\
\Omega & =+1 \text { and }-1 \text { for materials } 1 \text { and } 2, \text { respectively. } \\
\theta & =\text { Polar coordiante } \\
\sigma_{\mathrm{jk}} & =\text { stress tensor } \\
\sigma_{x 0}, \sigma_{y 0} & =\text { Normal stress components in the x- and } \mathrm{y} \text {-directions } \\
\omega_{\varepsilon_{j k}} & =\text { Matrix of real constants }
\end{array}
$$

\section{INTRODUCTION}

Laminated composite materials are widely used in engineering industries such as aerospace, marine and automobile. This is due to their high specific strength and stiffness. Layered dissimilar anisotropic materials also have a variety of applications in electronic devices such as micro-electro-mechanical systems (MEMS), semiconductors and optical electronics. However, debonding or cracking is the most common type of failure in layered materials during manufacturing or in-service applications. Williams ${ }^{1}$ was the first scientist to discover that the stress field along an interface crack between two dissimilar elastic materials is not only singular, but also has an oscillatory behavior of type $r^{-\frac{1}{2}+i \varepsilon}$ where $r$ is the radial distance from the crack tip and $\varepsilon$ is a bimaterial constant. His analytical approach was followed by Rice and $\mathrm{Sih}^{2}$, Erdogan and England $^{3-5}$ who mainly focused on linear elastic interfacial fracture mechanics 
(LEIFM) of isotropic materials. Clements ${ }^{6}$ and Willis ${ }^{7}$ extended the problem studied by England for dissimilar anisotropic materials. $\mathrm{Wu}^{8}, \mathrm{Qu}$ and $\mathrm{Li}^{9}, \mathrm{Qu}$ and Bassani ${ }^{10}$, Suo ${ }^{11}$, Ting ${ }^{12-13}$, and Beom and Atluri $^{14}$ expanded the theories of LEIFM for debonded anisotropic bimaterials. Following their pioneering research a variety of analytical and numerical approaches have been employed in this field ${ }^{15}$.

A bimaterial interface crack induces both opening and shearing behaviours even for a single mode loading. The strain energy release rate (SERR) per unit of the crack extension and stress intensity factors (SIFs) are of fundamental importance in the prediction of brittle failure using LEIFM. These depend on the crack geometry, associated loading and material properties. $\mathrm{K}_{1}$ and $\mathrm{K}_{2}$ are the mode I and mode II SIFs, respectively. They characterize stress fields in the vicinity of the crack tip with respect to a local Cartesian system $\left(a_{1}, a_{2}\right)$ that has its origin at the tip of the crack. $a_{1}, a_{2}$ are the axes in the tangent and transverse directions of the crack, respectively.

At present, the most commonly used method in industry for fracture analysis is the $J_{1}$-integral which is only applicable to straight cracks. Although it is less sensitive than the displacement method to the mesh size of the crack tip, it would still require stress analysis at internal points and fine contours around the crack front. Additionally, for mixed mode problems, auxiliary equations are required to decouple SIFs. An alternative is to evaluate the $J_{2}$-integral for separating SIFs. The $\mathrm{J}_{2}$-integral not only involves the computation of stresses and strains at a series of internal points around the crack but also the evaluation of highly singular integrals over the crack surfaces. For elastic problems with a straight crack, SERR is the same as $J_{1}$-integral which is the Rice's path independent integral $\left.\right|^{16-17}$. This method was first developed by Rice to characterize fractures for two-dimensional (2D) isotropic and homogeneous structures with linear and non-linear elastic material behavior.

A study by the author ${ }^{18}$ presents the novel application of the boundary element crack shape sensitivities (BECSS) for the evaluation of the $J_{1}$-integral in homogeneous and anisotropic materials where the crack of an arbitrary shape, 
straight or curve, was treated as the shape design variable. In another study ${ }^{19}$, using the BECSS coupled with an optimization algorithm and an automatic mesh generator, the crack kink angle and crack propagation path in anisotropic and homogeneous elastic solids were predicted. The maximum SERR criterion, best suited for anisotropic structures, was employed. In contrast to the $J_{1}$-integral method, the computation of stresses and strains at a series of internal points during the automatic incremental procedure was not required. By direct differentiation of the structural response ${ }^{20-23}$ the SERR at the existing crack tip and new cracks for the period of crack growth were determined. However, for decoupling of SIFs ${ }^{18-19}$, it was necessary to develop an auxiliary relationship in terms of displacement ratios near the crack tip to be used with the computed $J_{1}$ to separate SIFs. In Ref.[24] this deficiency was overcome by direct evaluation of the $\mathrm{J}_{2}$-integral using BECSS for isotropic and homogeneous materials. It was mathematically proved that the derivative of the total potential energy with respect to the transverse direction of the crack is not the $\mathrm{J}_{2}$-integral. However, by addition of an integral, involving the strain energy discontinuity, to this derivative, the $\mathrm{J}_{2}$-integral can be efficiently evaluated. This algorithm was then expanded and applied to the fracture analysis of interfacial cracks of dissimilar isotropic materials ${ }^{25}$. For bimaterials, it was proved that $\mathrm{J}_{2}$ is equal to the summation of the derivative of the total potential energy with respect to the transverse direction of the crack and two integrals involving crack tip elements. These integrals were related to the jump of displacement derivatives or strains across the interface and also the strain energy density (SED) discontinuity on the crack surfaces and interface region. The results show that the method is simple, accurate, flexible and applicable to both straight and curved cracks. Due to its generic nature, this algorithm ${ }^{25}$ can be expanded and applied to the fracture analysis of debonded anisotropic materials. However, an analytical expression relating $\mathrm{J}_{2}$ and SIFs is required to separate and calculate the corresponding SIFs which at present is non-existent.

In LEIFM, the majority of numerical and experimental methods rely mainly on the employed asymptotic field characterizing the stress and strain in the vicinity of the crack tip, and/or the analytical equations relating $J_{k}$-integrals and SIFs. For a 
linear elastic, isotropic and homogeneous material in mixed mode fracture, the SIFs and $J_{k}$-integrals are directly related and the corresponding analytical expressions are available ${ }^{26}$. Malyshev and Salganik ${ }^{27}$ derived an analytical expression relating $J_{1}$ and SIFs for an interfacial crack between two dissimilar homogeneous and isotropic materials. Gosz et $\mathrm{al}^{28}$ and Khandelwal and Chadra Kishen ${ }^{29}$ obtained an analytical expression for $\mathrm{J}_{2}$-integral in terms of SIFs for an interfacial crack between two dissimilar homogeneous and isotropic materials using the complex variable method. Wang et $\mathrm{al}^{30}$ and $\mathrm{Chu}$ and $\mathrm{Hong}^{31}$ showed that the $\mathrm{J}_{\mathrm{k}}$-integrals of a crack in a homogeneous anisotropic structure can be directly related to the corresponding SIFs. $\mathrm{Wu}^{8}$ and Suo ${ }^{11}$ presented an analytical expression for $J_{1}$ for an interfacial crack between two anisotropic bimaterial solids. For an interfacial crack in anisotropic bimaterials, the displacement and traction data near the crack tip are usually employed to compute $\mathrm{SIFs}^{32-37}$.

This paper presents a new analytical expression relating the $\mathrm{J}_{2}$-integral and the SIFs in an in-plane traction free crack between two orthotropic elastic solids using the complex function method. Using this new analytical expression, in conjunction with the values of $J_{k}$, allows for the computation of the corresponding SIFs without the need for an auxiliary relation.

\section{PLANE BIMATERIAL ANISOTROPIC ELASTICITY}

By combining the stress-strain relations, the compatibility equation of strains, and the equilibrium equation, the governing equation for the two-dimensional (2D) plane stress or plane strain state of homogeneous and anisotropic elasticity can be obtained ${ }^{38}$. To have a solution for the stress function, the following characteristic equation must be zero.

$S_{11} \mu^{4}-2 S_{16} \mu^{3}+\left(2 S_{12}+S_{66}\right) \mu^{2}-2 S_{26} \mu+S_{22}=0$.

$S_{j k}$ are the elastic compliances of the material. Lehknitskii ${ }^{38}$ has shown that for an anisotropic material, these roots are distinct and must be purely imaginary or complex. However, for a specially orthotropic material, these roots are purely imaginary

$\mu_{1}=i p_{1} \quad, \quad \mu_{2}=i p_{2} \quad, \quad \mu_{3}=\bar{\mu}_{1} \quad, \quad \mu_{4}=\bar{\mu}_{2}$ 
where $p_{1}$ and $p_{2}$ are real numbers.

For 2D in-plane linear elastic, homogeneous and anisotropic materials, the stress $\left(\sigma_{j k}\right)$ and displacement fields $\left(u_{j}\right)$ can be formulated ${ }^{11,39-40}$ in terms of two complex analytical functions $f_{j}\left(z_{j}\right)$ of the complex variable $z_{j}=x_{1}+\mu_{j} x_{2}(j=1,2)$ as

$$
\begin{aligned}
& u_{j}=\left[\begin{array}{l}
u_{1} \\
u_{2}
\end{array}\right]=2 \operatorname{Re}\left\{A\left[\begin{array}{l}
f_{1}\left(z_{1}\right) \\
f_{2}\left(z_{2}\right)
\end{array}\right]\right\} \\
& {\left[\sigma_{j 2}\right]=\left[\begin{array}{l}
\sigma_{12} \\
\sigma_{22}
\end{array}\right]=2 \operatorname{Re}\left[B\left[\begin{array}{l}
f_{1}^{\prime}\left(z_{1}\right) \\
f_{2}^{\prime}\left(z_{2}\right)
\end{array}\right]\right]} \\
& {\left[\sigma_{j 1}\right]=\left[\begin{array}{l}
\sigma_{11} \\
\sigma_{21}
\end{array}\right]=-2 \operatorname{Re}\left[B P\left[\begin{array}{l}
f_{1}^{\prime}\left(z_{1}\right) \\
f_{2}^{\prime}\left(z_{2}\right)
\end{array}\right]\right]}
\end{aligned}
$$

(Re) denotes the real part of a complex variable and a prime (')shows the derivative with respect to the associated arguments. The elements of complex matrices A, B and P for an aligned orthotropic material are defined as

$$
\begin{array}{ll}
A_{1 k}=S_{11} \mu_{k}^{2}+S_{12}-S_{16} \mu_{k} \quad, \quad A_{2 k}=S_{12} \mu_{k}+\frac{S_{22}}{\mu_{k}}-S_{26} \\
B_{1 k}=-\mu_{k} \quad, \quad B_{2 k}=1 \\
P_{k k}=\mu_{k} \quad, \quad P_{j k}=0 .(j \neq k)
\end{array}
$$

where $S_{16}=S_{26}=0^{20,21,38}$. Beom et al ${ }^{32}$ modified the Stroh formalism by introducing the complex functions $\mathrm{g}_{\mathrm{j}}(\mathrm{z})$ defined as,

$$
g(z)=\left[\begin{array}{l}
g_{1}(z) \\
g_{2}(z)
\end{array}\right]=B\left[\begin{array}{l}
f_{1}(z) \\
f_{2}(z)
\end{array}\right]
$$

Here the complex function $G(z)$ is designated as

$$
G(z)=g^{\prime}(z)=B\left[\begin{array}{l}
f_{1}^{\prime}(z) \\
f_{2}^{\prime}(z)
\end{array}\right]
$$

For an orthotropic material, 


$$
\Delta=i A B^{-1}=\left[\begin{array}{cc}
S_{11}\left(p_{1}+p_{2}\right) & i\left(\sqrt{S_{11} S_{22}}+S_{12}\right) \\
-i\left(\sqrt{S_{11} S_{22}}+S_{12}\right) & \frac{S_{22}\left(p_{1}+p_{2}\right)}{p_{1} p_{2}}
\end{array}\right]
$$

where $\Delta$ is a Hermitian matrix and can be written in terms of two real matrices $H$ and $Q$ as

$$
\Delta=H+i Q=\left[\begin{array}{cc}
S_{11}\left(p_{1}+p_{2}\right) & 0 \\
0 & \frac{S_{22}\left(p_{1}+p_{2}\right)}{p_{1} p_{2}}
\end{array}\right]+i\left[\begin{array}{cc}
0 & \left(\sqrt{S_{11} S_{22}}+S_{12}\right) \\
-\left(\sqrt{S_{11} S_{22}}+S_{12}\right) & 0
\end{array}\right]
$$

The matrix $\mathrm{H}$ is symmetric and positive definite and the matrix $\mathrm{Q}$ is antisymmetric.

Now consider a bimaterial solid consisting of two orthotropic materials. See Fig. 1a. Assume the principal axes of each material are coincident with the Cartesian coordinates axes, $x_{1}$ and $x_{2}$. For this bimaterial structure, two matrices $(\alpha, \beta)$ are required to define the stress fields at their interface ${ }^{12,14}$ which are,

$$
\begin{aligned}
& \alpha=(\stackrel{(1)}{H}+\stackrel{(2)}{H})^{-1}(\stackrel{(2)}{H}-\stackrel{(1)}{H})=\left[\begin{array}{cc}
\alpha_{11} & 0 \\
0 & \alpha_{22}
\end{array}\right] \\
& \beta=(\stackrel{(1)}{H}+\stackrel{(2)}{H})^{-1}(\stackrel{(2)}{Q}-\stackrel{(1)}{Q})=\left[\begin{array}{cc}
0 & \beta_{12} \\
\beta_{21} & 0
\end{array}\right]
\end{aligned}
$$

where

$$
\alpha_{11}=\frac{\stackrel{(2)}{H_{11}}-\stackrel{(1)}{H_{11}}}{\stackrel{(1)}{H}_{11}+\stackrel{(2)}{H_{11}}}, \alpha_{22}=\frac{\stackrel{(2)}{H_{22}}-\stackrel{(1)}{H_{22}}}{\stackrel{(1)}{H}_{22}+\stackrel{(2)}{H}_{22}}, \beta_{12}=\frac{\stackrel{(2)}{Q_{12}}-\stackrel{(1)}{Q_{12}}}{H_{11}+\stackrel{(1)}{H}_{11}}, \beta_{21}=\frac{\stackrel{(2)}{Q_{21}}-\stackrel{(1)}{Q_{21}}}{\stackrel{(2)}{H}_{22}+\stackrel{(1)}{H}_{22}}
$$

the superscript indicates the material number. The elements of matrices $\stackrel{(n)}{H}$ and $\stackrel{(\mathrm{n})}{\mathrm{Q}}$ $(n=1,2)$ are given by equation 10 and

$\beta_{12} \beta_{21}=-\beta_{0}^{2}$

$\beta_{0}$ is a dimensionless bimaterial parameter. For an isotropic bimaterial case, $\alpha$ and $\beta$ reduce to $\alpha=\left[\begin{array}{cc}\alpha_{0} & 0 \\ 0 & \alpha_{0}\end{array}\right], \beta=\left[\begin{array}{cc}0 & \beta_{0} \\ -\beta_{0} & 0\end{array}\right]$ where $\alpha_{0}$ and $\beta_{0}$ are Dundor parameters $^{41}$. 


\section{REVIEW OF THE RELATIONS BETWEEN $J_{k}$-INTEGRAL AND SIFS FOR DIFFERENT ENGINEERING MATERIALS}

For a $2 \mathrm{D}$ in-plane linear or non-linear elastic material of unit thickness, the $\mathrm{Jk}_{\mathrm{k}}$ integrals are the line integrals evaluated along a counterclockwise contour (s) enclosing and shrinking onto the crack tip defined as

$$
J_{k} \equiv \lim _{r \rightarrow 0} \oint_{S}\left(W n_{k}-t_{j} u_{j, k}\right) d s
$$

where $j, k=1,2$. W is the SED, $n_{k}$ are the components of the unit outward normal to the contour path, $\mathrm{t}_{\mathrm{j}}$ and $\mathrm{u}_{\mathrm{j}}$ are the traction and displacement components along the path. For a straight crack, $J_{1}$-integral is the SERR along the crack.

For a linear elastic, isotropic and homogeneous material in mixed mode fracture, the SIFs and $J_{k}$-integrals are related by the following relations ${ }^{26}$,

$$
\begin{aligned}
& J_{1}=\frac{K_{1}^{2}+K_{2}^{2}}{E} \\
& J_{2}=-\frac{2 K_{1} K_{2}}{E}
\end{aligned}
$$

Malyshev and Salganik ${ }^{27}$ were the first scientists to find an analytical expression relating $J_{1}$ and SIFs for interfacial cracks between two dissimilar homogeneous and isotropic materials as

$$
J_{1}=\frac{1}{2(\cosh \pi \varepsilon)^{2}}\left[\frac{1}{\frac{(1)}{E}}+\frac{1}{\frac{(2)}{E}}\right]\left(K_{1}^{2}+K_{2}^{2}\right) \text { where } \frac{1}{\frac{(n)}{E}}=\left[\begin{array}{cc}
\frac{1}{(n)} & \text { Planestress } \\
E & \\
\frac{1-\left(\begin{array}{l}
(n) \\
\left.v^{2}\right)
\end{array}\right.}{E} & \text { Planestrain } \\
E &
\end{array}\right.
$$

where $\stackrel{(n)}{E}(\mathrm{n}=1,2)$ is the modulus of elasticity of each material.

Using the complex variable method, Gosz et $\mathrm{al}^{28}$ and Khandelwal and Chadra Kishen ${ }^{29}$ showed that $\mathrm{J}_{2}$-integral can also be expressed in terms of the SIFs for interfacial cracks between two dissimilar homogeneous and isotropic materials as 


$$
\begin{aligned}
J_{2}=-\frac{1}{4 \pi \varepsilon(\cosh \pi \varepsilon)^{2}}[ & \frac{1}{(1)}\left(1-e^{-2 \pi \varepsilon}\right)+\frac{1}{E}\left(\frac{2)}{E}\left(e^{2 \pi \varepsilon}-1\right)\right] \times \\
& {\left[\left(K_{1}^{2}-K_{2}^{2}\right) \sin (2 \varepsilon \ln r)+2 K_{1} K_{2} \cos (2 \varepsilon \ln r)\right] }
\end{aligned}
$$

Equation 18 shows that $J_{2}$ depends on $\mathrm{r}$, has an oscillatory variation and is nonexistent when $r \rightarrow 0$.

Wang et $\mathrm{al}^{30}$ and Chu and Hong ${ }^{31}$ showed that the $\mathrm{J}_{\mathrm{K}}$-integral of a crack in an inplane homogeneous and anisotropic structure can be related to the corresponding SIFs by

$$
\begin{aligned}
& J_{1}=a_{11} K_{1}^{2}+a_{12} K_{1} K_{2}+a_{22} K_{2}^{2} \\
& J_{2}=b_{11} K_{1}^{2}+b_{12} K_{1} K_{2}+b_{22} K_{2}^{2}
\end{aligned}
$$

where the coefficients $a_{j k}$ and $b_{j k}$ are defined in appendix $A$.

Wuo ${ }^{8}$ and $S_{10}{ }^{11}$ presented an analytical expression for $J_{1}$ for an interfacial crack between two orthotropic bimaterial solids as

$$
J_{1}=\frac{1}{4(\cosh \pi \varepsilon)^{2}}\left[\left(\stackrel{(2)}{H_{11}}+\stackrel{(1)}{H}\right) K_{11}^{2}+\left(\stackrel{(2)}{H_{22}}+\stackrel{(1)}{H_{22}}\right) K_{1}^{2}\right]
$$

Equations 14-21 have been used by academics and industrialists worldwide in relation to the fracture analyses of engineering structures. At present, there is no analytical expression relating $J_{2}$ and the SIFs for cracks between dissimilar anisotropic or orthotropic solids.

\section{INTERFACIAL CRACK BETWEEN ORTHOTROPIC SOLIDS AND INTERFACE SIFS}

Fig. 1b shows a straight crack lying along the interface between two linear elastic, homogeneous and orthotropic solids, of materials (1) and (2), respectively. The Cartesian coordinate system $\left(\mathrm{x}_{1}, \mathrm{x}_{2}\right)$ has its origin (o) at the tip of the crack and the interface is assumed to be bonded perfectly. The crack and 
the interface both lie along the $x_{1}$-axis. The principal axes of both materials are assumed to be coincident with $\mathrm{x}_{1}$ and $\mathrm{x}_{2}$.

The complex analytical functions generating the singular fields near the tip of an interface crack between two dissimilar orthotropic materials can be expressed as $^{8,9,12,14,32}$

$\stackrel{(n)}{G(z)}=\frac{1}{2 \sqrt{2 \pi z}}(I+\Omega i \beta) \mathrm{Y}\left(z^{i \varepsilon}, z^{-i \varepsilon}\right) K$

$\Omega$ is equal to +1 and -1 for materials 1 and 2 , respectively. I is a unit matrix and $\varepsilon$ is an oscillatory bimaterial index defined as

$\varepsilon=\frac{1}{2 \pi} \operatorname{Ln} \frac{1+\left|\beta_{0}\right|}{1-\left|\beta_{0}\right|}$

$\mathrm{K}$ is the vector of interface SIFs and $\mathrm{Y}$ is the complex matrix function representing the oscillatory field. $\mathrm{K}$ and $\mathrm{Y}$ are defined as

$$
\begin{aligned}
& \mathrm{Y}\left(z^{i \varepsilon}, z^{-i \varepsilon}\right)=\frac{1}{2}\left(z^{i \varepsilon-\frac{1}{2}}+z^{-i \varepsilon-\frac{1}{2}}\right) I+\frac{i}{2\left|\beta_{0}\right|}\left(z^{i \varepsilon-\frac{1}{2}}-z^{-i \varepsilon-\frac{1}{2}}\right) \beta \\
& K=\left[\begin{array}{c}
K_{2} \\
K_{1}
\end{array}\right]=\lim _{x_{1} \rightarrow 0} \sqrt{2 \pi x_{1}} Y\left(x_{1}^{-i \varepsilon}, x_{1}^{i \varepsilon}\right)\left[\begin{array}{l}
\sigma_{21}\left(x_{1}, 0\right) \\
\sigma_{22}\left(x_{1}, 0\right)
\end{array}\right]
\end{aligned}
$$

Substituting equations 12 and 24 into equation 22 and designating the complex functions $D_{1}, D_{2}, \stackrel{(n)}{\psi}, \stackrel{(n)}{\phi}$ as

$$
\begin{aligned}
& D_{1}(z)=z^{i \varepsilon-\frac{1}{2}}+z^{-i \varepsilon-\frac{1}{2}}, D_{2}(z)=z^{i \varepsilon-\frac{1}{2}}-z^{-i \varepsilon-\frac{1}{2}}, \\
& \stackrel{(n)}{\psi}(z)=D_{1}(z)+\Omega\left|\beta_{0}\right| D_{2}(z), \stackrel{(n)}{\phi}(z)=\Omega D_{1}(z)+\frac{D_{2}(z)}{\left|\beta_{0}\right|}
\end{aligned}
$$

Equation 22 becomes,

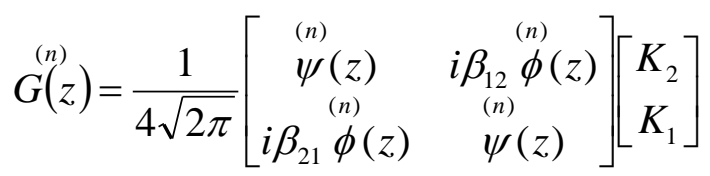

Or

$$
G_{(z)}^{(z)}=\frac{1}{4 \sqrt{2 \pi}} \stackrel{(n)}{L} K
$$


where the complex matrix $\stackrel{(n)}{L}$ is defined as

$$
\stackrel{(n)}{L}=\left[\begin{array}{cc}
\stackrel{(n)}{\psi(z)} & i \beta_{12} \stackrel{(n)}{\phi}(z) \\
i(n) & (n) \\
i \beta_{21} \stackrel{(z)}{(z)} & \psi(z)
\end{array}\right]
$$

\section{EVALUATION OF $\mathrm{J}_{\mathrm{K}}$-INTEGRALS FOR DEBONDED ORTHOTROPIC SOLIDS USING THE COMPLEX FUNCTUION METHOD}

As mentioned earlier, an analytical expression for $J_{1}$ (Eq. 21) in debonded orthotropic bimaterials is already available. However, for the sake of clarity here, $J_{1}$ is also derived using the complex function method. Figs. 2a-b show two narrow rectangular contours $s_{1}$ and $s_{2}$ for evaluation of $J_{1}$ and $J_{2}$, respectively ${ }^{42}$. Based on these contours, equation 14 for $J_{1}$ and $J_{2}$ can be reduced to

$$
\begin{aligned}
& J_{1}=-\lim _{\substack{R \rightarrow 0 . \\
\delta / R \rightarrow 0}} \oint_{s_{1}}\left(\sigma_{j 2}^{T} u_{j, 1}\right)\left(n_{2}\right) d s \\
& J_{2}=-\lim _{\substack{R \rightarrow 0 . \\
\delta / R \rightarrow 0}} \oint_{s_{2}}\left(\sigma_{j 1}^{T} u_{j, 2}\right)\left(n_{1}\right) d s
\end{aligned}
$$

As shown in Fig. $2 \mathrm{a}$, for contour $\mathrm{s}_{1}, x_{2} \approx 0$, therefore

$z_{1}=z_{2}=z,\left(n_{2}\right) d s=-d z$

Based on equations $3,4,8,9$ and 22, the stress and displacement derivative vectors for each material are

$$
\begin{aligned}
\left(\sigma_{j 2}^{T}\right)^{(n)} & =2 \operatorname{Re}[G(z)]^{(n)}=(G(z)+\overline{G(z)})^{(n)} \\
\left(u_{j, 1}\right)^{(n)} & =\left[\begin{array}{l}
\frac{\partial u_{1}}{\partial x_{1}} \\
\frac{\partial u_{2}}{\partial x_{1}}
\end{array}\right]^{(n)}=2 \operatorname{Re}\left\{A B^{-1} G(z)\right\}^{(n)}=(-i \Delta G(z)+i \bar{\Delta} \overline{G(z)})^{(n)}
\end{aligned}
$$

Substituting equations $32-34$ into equation 30 gives

$$
J_{1}=-\oint\left(G^{T}(z)+\overline{G^{T}(z)}\right){ }^{(n)}(-i \Delta G(z)+i \bar{\Delta} \overline{G(z)})^{(n)} d z
$$

As shown in Fig. 1b, for material-1, $0 \leq \theta \leq \pi$, and for material-2, $-\pi \leq \theta \leq 0$.

According to the complex integrals (B-1) shown in Appendix B, for $c_{1}=c_{2}=c=1$, equation 35 can be written as 
$J_{1}=i \oint\left(G^{T}(z) \Delta G(z)-\overline{G(z)^{T}} \bar{\Delta} \overline{G(z)}\right)^{(n)} d z$

or

$$
J_{1}=-2 \operatorname{Im}\left\{\oint\left[G^{T}(z) \Delta G(z)\right]^{(n)} d z\right\}
$$

Substituting equation 28 into equation 37 we have,

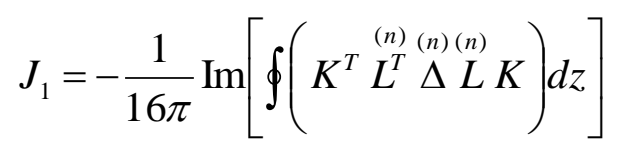

Inserting the elements of matrices $L$ and $\Delta$ into equation $38, J_{1}$ becomes

$$
\begin{aligned}
J_{1}=-\frac{1}{16 \pi} \oint\{ & K_{2}^{2}\left[\stackrel{(n)}{H_{11}} \psi^{2}(z)-\stackrel{(n)}{H_{22}} \beta_{21}^{2} \phi^{2}(z)\right]+K_{1}^{2}\left[\stackrel{(n)}{H_{22}} \psi^{2}(z)-\stackrel{(n)}{H_{11}} \beta_{12}^{2} \phi^{2}(z)\right] \\
& \left.\left.+2 i K_{1} K_{2}\left[\beta_{12} \stackrel{(n)}{H_{11}}+\beta_{21} \stackrel{(n)}{H}_{22}\right] \phi(z)\right) \psi^{(n)}(z)\right\} d z
\end{aligned}
$$

Since $\beta_{12}=-\beta_{21} \frac{\stackrel{(1)}{22}_{21}+H_{22}^{(2)}}{H_{11}+\stackrel{(2)}{H_{11}}}$ and based on the complex integrals B-2 and C-1 shown in appendices $B$ and $C$, respectively, equation 39 can be simplified to $J_{1}=\frac{1}{4}\left(1-\beta_{0}^{2}\right)\left\{\left(\stackrel{(1)}{H_{11}}+\stackrel{(2)}{H_{11}}\right) K_{2}^{2}+\left(\stackrel{(1)}{H_{22}}+\stackrel{(2)}{H_{22}}\right) K_{1}^{2}\right\}$

Equation 40 is identical to equation 21.

The next stage is the derivation of $J_{2}$ using equation 31 . As shown in Fig. $2 b$, for contour $\mathrm{s}_{2}, x_{1} \approx 0$, therefore,

$z_{1}=-i \mu_{1} z, z_{2}=-i \mu_{2} z,\left(n_{1} d s\right)=-i d z$

Based on equations 3 and 5 , the stress and displacement derivative vectors for each material can be written as

$$
\begin{aligned}
& \left(u_{j, 2}\right)^{(n)}=\left[\begin{array}{l}
\frac{\partial u_{1}}{\partial x_{2}} \\
\frac{\partial u_{2}}{\partial x_{2}}
\end{array}\right]^{(n)}=2 \operatorname{Re}\left\{A P\left[\begin{array}{l}
f_{1}^{\prime}\left(z_{1}\right) \\
f_{2}^{\prime}\left(z_{2}\right)
\end{array}\right]\right\}^{(n)} \\
& {\left[\sigma_{j 1}\right]^{(n)}=\left[\begin{array}{l}
\sigma_{11} \\
\sigma_{21}
\end{array}\right]^{(n)}=-2 \operatorname{Re}\left[B P\left[\begin{array}{l}
f_{1}^{\prime}\left(z_{1}\right) \\
f_{2}^{\prime}\left(z_{2}\right)
\end{array}\right]\right]^{(n)}}
\end{aligned}
$$

By combining equations 8 and 27 we have, 


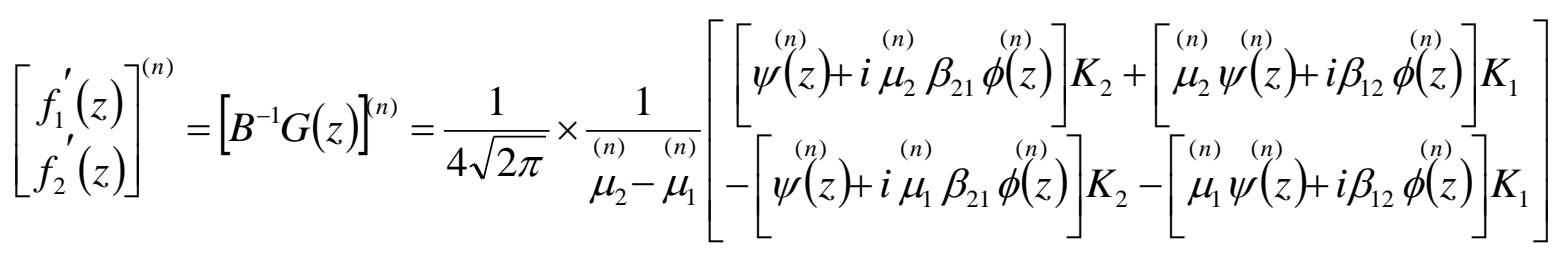

In order to evaluate the stress and displacement derivative vectors of each material using equations 42-43, $f_{1}^{\prime}(z)$ and $f_{2}^{\prime}(z)$ in the above relation must be written in terms of $z_{1}$ and $z_{2}$, respectively, as

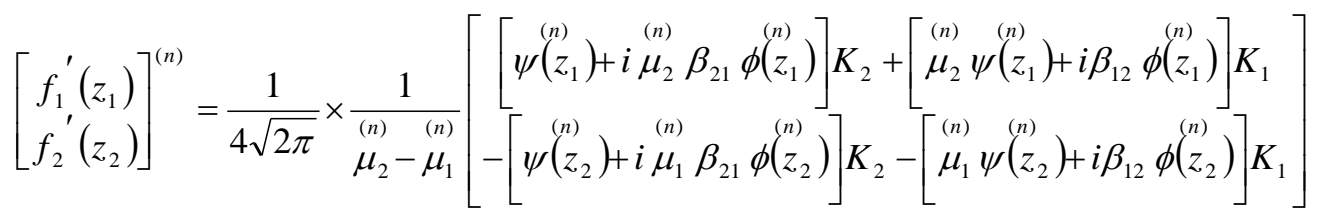

Next for the ease of integration, using equations 41 and the complex functions $\psi_{j}(z)$ and $\phi_{j}(z)(\mathrm{j}=1,2)$ defined in appendix D, Eq. 45 can be written in the form,

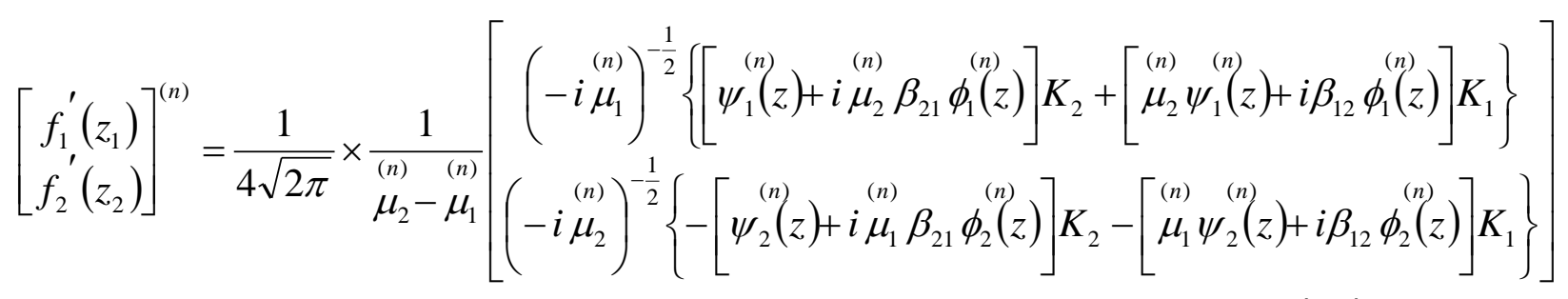

By defining two new matrices $\stackrel{(n)}{q}$ and $\stackrel{(n)}{M}$ as

$$
\begin{aligned}
& \stackrel{(n)}{q}=\left[\begin{array}{cc}
\frac{1}{\sqrt{\mu_{1}}\left(\mu_{2}-\mu_{1}\right)} & 0 \\
0 & \frac{1}{\sqrt{\mu_{2}}\left(\mu_{2}-\mu_{1}\right)}
\end{array}\right]^{(n)}
\end{aligned}
$$

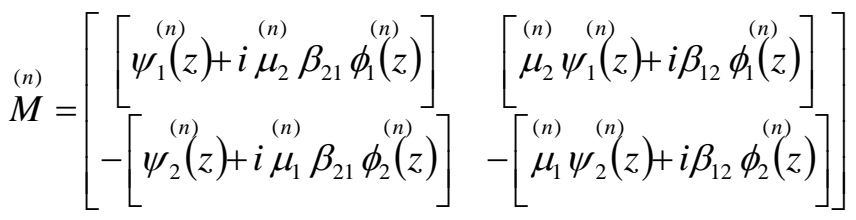

Equation 46 can be written in the form,

$$
\left[\begin{array}{l}
f_{1}^{\prime}\left(z_{1}\right) \\
f_{2}^{\prime}\left(z_{2}\right)
\end{array}\right]^{(n)}=\frac{1}{4 \sqrt{2 \pi}} \times \frac{1}{\sqrt{-i}} \times \stackrel{(n)(n)}{q M} K
$$


After substituting equation 49 into equations 42 and 43 , the stress and displacement derivative vectors can be written as

$$
\begin{aligned}
& {\left[\sigma_{j 1}\right]^{(n)}=\frac{-1}{4 \sqrt{2 \pi}} 2 \operatorname{Re}\left[\frac{1}{\sqrt{-i}} \stackrel{(n)(n)(n)(n)}{P} \stackrel{M}{q} K\right]=\frac{-1}{4 \sqrt{2 \pi}}\left(\frac{1}{\sqrt{-i}} \stackrel{(n)(n)(n)(n)}{P} \stackrel{(n)}{M} K+\frac{1}{\sqrt{i}} \frac{(n)(n)}{B} \stackrel{(n)}{P} \frac{(n)}{M} K\right)}
\end{aligned}
$$

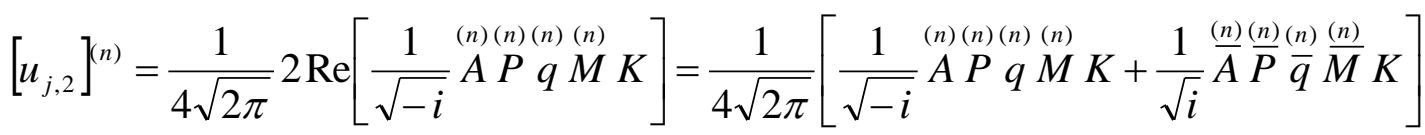

In order to derive $J_{2}$, equations $50-51$ are inserted into equation 31 and based on the complex integrals B-1 in Appendix B we have,

$$
J_{2}=\frac{1}{32 \pi}\left[\oint\left(K^{T} M^{T} q^{T} P^{T} B^{T} \stackrel{(n)(n)(n)}{A} \stackrel{(n)}{M} K-K^{T} \frac{(n)}{M^{T}} \bar{q}^{T}{ }^{T} \bar{P}^{T} \frac{(n)}{B^{T}} \stackrel{(n)}{A} \frac{(n)}{P} \frac{(n)}{q} \frac{(n)}{M} K\right) d z\right]
$$

or

$$
J_{2}=2 \times \frac{-1}{32 \pi} \operatorname{Im}\left[\frac{1}{i} \oint\left(K^{T} M^{T} q^{T} P^{T} B^{T} A P q M K\right) d z\right]
$$

By designating the matrix $\omega_{c}$ as

$$
\omega_{\varepsilon}=q^{T} P^{T} B^{T} A P q=\left[\begin{array}{ll}
\omega_{\varepsilon_{\varepsilon_{11}}} & \omega_{\varepsilon_{12}} \\
\omega_{\varepsilon_{21}} & \omega_{\varepsilon_{22}}
\end{array}\right]
$$

Equation 53 can be written as

$$
J_{2}=-\frac{1}{16 \pi} \operatorname{Im}\left[\frac{1}{i} \oint\left(K^{T} M^{T} \omega_{\varepsilon} M K\right) d z\right]
$$

As shown in appendix $\mathrm{E}$, all the elements of the matrix $\omega_{\varepsilon}$ are real and depend mainly on the engineering constants and characteristic roots of the materials where

$$
\begin{aligned}
& \omega_{\varepsilon_{11}}=. \frac{S_{22}-S_{11} \mu_{1}^{4}}{\left(\mu_{2}-\mu_{1}\right)^{2}} \\
& \omega_{\varepsilon_{22}}=\frac{S_{22}-S_{11} \mu_{2}^{4}}{\left(\mu_{2}-\mu_{1}\right)^{2}} \\
& \omega_{\varepsilon_{12}}+\omega_{\varepsilon_{21}}=0 .
\end{aligned}
$$


After substituting the elements of matrices $q, M$ and $\omega$ into equation $55, \mathrm{~J}_{2}$ becomes

$$
\begin{aligned}
& J_{2}=-\frac{1}{16 \pi} \operatorname{Im}\left\{\frac { 1 } { i } \oint \left[\left(\begin{array}{cccc}
(n) & (n) & (n) & (n) \\
\omega_{\varepsilon_{11}} & M_{12}^{2}+\omega_{\varepsilon_{22}} & M_{22}^{2}
\end{array}\right) K_{1}^{2}+\left(\begin{array}{cccc}
(n) & (n) & (n) & (n) \\
\omega_{\varepsilon_{11}} & M_{11}^{2}+\omega_{\varepsilon_{22}} & M_{21}^{2}
\end{array}\right) K_{2}^{2}\right.\right.
\end{aligned}
$$

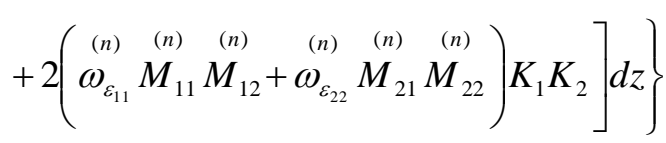

According to the complex integrals presented in appendix $F, J_{2}$ is derived as

$$
J_{2}=\Lambda_{\varepsilon_{11}} K_{2}^{2}+\Lambda_{\varepsilon_{22}} K_{1}^{2}+2 \Lambda_{\varepsilon_{12}} K_{1} K_{2}
$$

where

$$
\begin{aligned}
& \Lambda_{\varepsilon_{11}}=\frac{1}{8 \pi \varepsilon} \sum_{n=1}^{2}\left\{\stackrel{(n)}{\omega_{\varepsilon_{11}}}\left[\Omega \beta_{0}^{2}+\Omega \stackrel{(n)}{p_{2}^{2}} \beta_{21}^{2}-2 \stackrel{(n)}{p_{2}} \beta_{21}\right] \sin 2 \varepsilon \ln \stackrel{(n)}{p_{1}} r+\stackrel{(n)}{\omega_{\varepsilon_{22}}}\left[\Omega \beta_{0}^{2}+\Omega \stackrel{(n)}{p_{1}^{2}} \beta_{21}^{2}-2 \stackrel{(n)}{p_{1}} \beta_{21}\right] \sin 2 \varepsilon \ln \stackrel{(n)}{p_{2}} r\right\} \\
& \Lambda_{\varepsilon_{22}}=\frac{-1}{8 \pi \varepsilon} \sum_{n=1}^{2}\left\{{ }^{(n)} \omega_{\varepsilon_{11}}\left[\Omega \beta_{12}^{2}+\Omega \stackrel{(n)}{p_{2}^{2}} \beta_{0}^{2}+2 \stackrel{(n)}{p_{2}} \beta_{12}\right] \sin 2 \varepsilon \ln \stackrel{(n)}{p_{1}} r+\stackrel{(n)}{\omega_{\varepsilon_{22}}}\left[\Omega \beta_{12}^{2}+\Omega \stackrel{(n)}{p_{1}^{2}} \beta_{0}^{2}+2 \stackrel{(n)}{p_{1}} \beta_{12}\right] \sin 2 \varepsilon \ln \stackrel{(n)}{p_{2}} r\right\} \\
& \Lambda_{\varepsilon_{12}}=\frac{\left|\beta_{0}\right|}{8 \pi \varepsilon} \sum_{n=1}^{2}\left\{\omega_{\varepsilon_{11}}^{(n)}\left[\Omega \beta_{12}-\Omega \stackrel{(n)}{2} p_{2}^{2} \beta_{21}+2 \underset{p_{2}}{\omega_{2}}\right] \cos 2 \varepsilon \ln \stackrel{(n)}{p}_{1} r+\stackrel{(n)}{\omega}_{\varepsilon_{22}}\left[\Omega \beta_{12}-\Omega \stackrel{(n)}{p_{1}^{2}} \beta_{21}+2 p_{1} p_{1}^{(n)} \cos 2 \varepsilon \ln \stackrel{(n)}{p}_{2} r\right\}\right.
\end{aligned}
$$

Equation 58 is an analytical expression for $J_{2}$ in terms of SIFs for an in-plane traction free crack between two orthotropic elastic solids.

Equations 40 and 58 can be combined and then re-arranged with respect to $K_{1}$ and $\mathrm{K}_{2}{ }^{25}$. Once $\mathrm{J}_{\mathrm{k}}$ values are obtained numerically using BEM or FEM, SIFs can be calculated. The signs of SIFs can be determined by checking the values of the crack opening displacements near the crack tip.

\section{INTERFACIAL CRACK IN AN ORTHOTROPIC BIMATERIAL PLATE}

An example of an interface crack between two dissimilar orthotropic materials is analysed to show the variation of $J_{2}$ in the vicinity of the crack tip. Different bimaterial combinations are considered to demonstrate the effect of elastic properties and material mismatch on $\mathrm{J}_{\mathrm{k}}$.

Fig. 3 shows a crack, with the length $2 a=20 \mathrm{~mm}$, centred at the origin in a thin bimaterial plate consisting of Material-1 (top) and Material-2 (bottom) under a 
tensile stress of $\sigma_{y 0}=100 \mathrm{MPa} . \mathrm{H}$ and $\mathrm{W}$ are the width and height of the plate, respectively. It is assumed that $\mathrm{a} / \mathrm{W}$ and $\mathrm{H} / \mathrm{W}$ are small enough for the plate to be considered an infinite plate. The plane stress condition is also assumed. To ensure strain continuity along the bimaterial interface, in the infinite plate solution, $\left(\sigma_{x}\right)_{0}$ must be prescribed on the side of material-2, as shown in Fig. $3^{2,25}$. Table 1 shows the engineering constants for several composite materials ${ }^{43}$. As shown, seven different bimaterial combinations are arranged. Material-1 is designated as pitch graphite/epoxy (p-100/ERL-1962) and Material2 varies from cases 1 to 7 . The characteristic roots of each composite and the mismatch parameter $\varepsilon$ for each bimaterial are also given in Table 1.

The exact analytical solution for SIFs of an infinite anisotropic bimaterial plate with a central interface crack is given by $\mathrm{Qu}$ and Bassani ${ }^{10}$ as,

$$
\left.K=\sqrt{\pi a} \mathrm{Y} \mid(1+2 i \varepsilon)(2 a)^{-i \varepsilon} \llbracket \sigma_{j 2}\right]_{0}
$$

where $\left(\sigma_{12}\right)_{0}=0$. and $\left(\sigma_{22}\right)_{0}=\sigma_{y_{0}}$. For selected biamterial cases, the analytical values of $\mathrm{J}_{2}$ are calculated using equations 58 and 60 when $10^{-6} \leq \frac{r}{a} \leq 10^{-3}$ and illustrated in Fig. 4. It can be observed that $J_{2}$ has a sharp variation near the crack tip and relatively a smooth change away from the crack tip.

Fig. 5 shows the variation of the $J_{k}$ with respect to $\varepsilon$. $J_{2}$ curves are evaluated for $\frac{r}{a}=10^{-6}, 10^{-5}, 10^{-4}$ and $10^{-3}$. It can be observed that both $\mathrm{J}_{1}$ and $\mathrm{J}_{2}$ almost show the same trend of variation. Except for the bimaterial 3, the higher $\varepsilon$ is the higher $J_{k}$ is. Table 2 shows the SIF values of each bimaterial plate.

As discussed before, the $J_{k}$-integrals can be interpreted as the SERRs associated with the crack shape variation in the $a_{k}$ directions. In a recent study by the author ${ }^{24-25}$, the $J_{k}$ values for isotropic bimaterials were successfully computed using BECSS and with the available analytical expressions the 
corresponding SIFs were calculated. Due to its generic application, that algorithm can be expanded to compute the $J_{k}$ values of an interfacial crack in dissimilar orthotropic materials using BECSS. Using the analytical expression for the $J_{2}$-integral presented in this paper and in conjunction with the values of $J_{k}$, the corresponding SIFs for an in-plane traction free crack between two orthotropic elastic solids can be computed without the need for an auxiliary relation.

Although LEFM, based on the plane theory of elasticity, provides good approximate solutions for a wide range of engineering structures, in some cases 3D treatment of flaws can deliver more realistic and accurate results [44]. A comprehensive review of analytical, numerical and experimental research by Pook [45] shows the three-dimensional (3D) effects at cracks and sharp notches. This review [45] is mainly focused on linear elastic, homogeneous and isotropic materials. Therefore, further research is required to expand BECSS and its relevant analytical relations for the $3 \mathrm{D}$ analysis of LEIFM of anisotropic bimaterial structures.

The $J_{1}$-integral can also be employed for the analysis of notches in plane linear and nonlinear elasticity problems. Rice [16] showed that the $J_{1}$-integral at $U$ notches is also path-independent. The local strain energy density (SED) approach was originally proposed by Lazzarin and Zamabardi [46] for pointed and blunt $V$-notches subjected to uniaxial loading and subsequently was extended to muiltiaxial loadings [47]. They showed that the average value of SED in the small volume around a notch is a measure of the characterization of the initiation of fracture failure. Lazzarin et al [48] extended the $J_{1}$-integral concept from cracks to pointed V-notches. As both local SED and $J_{1}$ values characterize crack initiation at notches, Lazzarin et al [49] derived the relation between $J_{1}$ and local SED of sharp and blunt V-notches. Ref.[50] is a comprehensive review by Radaj on the local SED concept and its relation to the $\mathrm{J}_{1}$-integral. Another option for further study is the application of BECSS and its relevant analytical relations for the analysis of notches in anisotropic homogeneous and bimaterial structures. 


\section{CONCLUSIONS}

First, a brief review of LEIFM for in-plane anisotropic bimaterials has been made. Next, using the complex function method, an analytical expression between $\mathrm{J}_{2^{-}}$ integral and the mixed-mode SIFs at the tip of an interface crack in debonded orthotropic elastic solids is presented. To the author's knowledge, this expression has not been previously published. Computation of $J_{1}$ is not adequate for calculation of SIFs. Using this analytical expression in conjunction with the values of $J_{1}$ and $J_{2}$ allows for the corresponding SIFs to be computed without the need for an auxiliary relation. Similar to the example presented in this paper, provided the SIFs are already available, by using this expression a very accurate value of $J_{2}$ can be obtained. This information can facilitate the prediction of the crack kink angle and propagation path of interface cracks in orthotropic bimaterials. Finally, an example with known analytical solutions for SIFs is presented to show the variation of $\mathrm{J}_{2}$-integral near the crack tip of a bimaterial orthotropic plate using the available SIFs. Different bimaterial combinations are considered and the effect of material mismatch on $J_{k}$ is demonstrated.

At present, the most commonly used method in industry for fracture analysis is the $J_{1}$-integral which is only applicable to straight cracks. Although it is less sensitive than the displacement method to the mesh size of the crack tip, it would still require stress analysis at internal points and fine contours around the crack front. Additionally, for mixed mode problems, auxiliary equations are required to separate SIFs. For an interfacial crack in anisotropic bimaterials, the displacement and traction data near the crack tip are usually employed to decouple and compute SIFs. In a recent study by the author, it was shown that the $J_{k}$-integrals can be interpreted as the SERRs associated with the crack shape variation in the $a_{k}$ directions and can be computed using the BECSS for straight and curved cracks. Due to its generic application, that algorithm can be expanded to compute the $\mathrm{J}_{\mathrm{k}}$ values of an interfacial crack in dissimilar anisotropic materials. With the analytical expression for the $J_{2}$-integral presented in this paper and in conjunction with the values of $J_{k}$ computed using BECSS, the corresponding SIFs for an in-plane traction free crack between two orthotropic elastic solids can be obtained without the need for an auxiliary relation. In the 
future, it would be ideal to obtain an analytical expression for the $J_{2}$-integral of an interface crack in debonded anisotropic solids.

\section{REFERENCES}

1. Williams M.L. (1959) The stresses around a fault or crack in dissimilar media. Bull. Seismol. Soc. Am. 49c, 199-204.

2. Rice, J.R. and G.C. Sih (1965) Plane problems of cracks in dissimilar media. J. App. Mech. 32, 418-423.

3. Erdogan, F. (1963) Stress distribution in a nonhomogeneous elastic plane with cracks. Trans. ASME, J. Appl. Mech.,30, 232-236.

4. Erdogan, F. (1965) Stress distribution in bonded dissimilar materials with crack. J. Appl. Mech., 32, 403-409.

5. England, A.H. (1965) A crack between dissimilar media. ASME, J. Appl Mech., 32, 400-402.

6. Clements, D.L. (1971) A crack between dissimilar anisotropic media. Int. J. Engng Sci, 9, 257-265.

7. Willis, J.R. (1971) Fracture mechanics of interfacial crack. J. Mech. Phys. Solids, 19 , 353-368.

8. Wu, K.C. (1990) Stress intensity factor and energy release rate for interfacial cracks between dissimilar anisotropic materials. J. Appl. Mech., 57, 882-886.

9. Qu, J. and Li, Q. (1991) Interfacial dislocation and its application to interface cracks in anisotropic bimaterials. J. elasticity, 26, 169-195.

10. Qu, J., and Bassani J.L. (1993) Interfacial fracture mechanics for anisotropic bimaterials. J. Appl. Mech., 60, 422-431.

11. Suo, Z. (1990) Singularities, interfaces and cracks in dissimilar anisotropic media. Proc. R. Soc. Lond., A , 427, 331-358.

12. Ting, T.C.T. (1995) Generalized Dundors constants for anisotropic bimaterials. Int. J. Solids Struct., 32, 483-500.

13. Ting, T.C.T (1986) Explicit solution and invariance of the singularities at an interface crack in anisotropic composites. Int.J. Solids and Struct., 22, 965-983. 
14. Beom, H. G. and Atluri, S.N. (1995) Dependence of stress on elastic constants in an anisotropic bimaterial under plane deformation; and the interfacial crack. Comput. Mech., 16, 106-113.

15. Banks-Sills, L. (2015) Interface fracture mechanics: theory and experiment. Int. J. of Fract., 191, 131-146.

16. Rice J.R. (1968) A path independent integral and the approximate analysis of strain concentration by notches and cracks. J Appl. Mech., 35, 379-386.

17. Rice, J.R. (1968) Mathematical Analysis in the Mechanics of Fracture. In: H. Liebowitz (Ed.), Treatise on Fracture, second ed., Academic Press, NY., , 191-311.

18. Tafreshi, A. (2009) Fracture Mechanics Analysis of Composite Structures Using the Boundary Element Shape Sensitivities. AIAA J, 47(8), 19261938.

19. Tafreshi, A. (2011) Simulation of crack propagation in anisotropic structures using the boundary element shape sensitivities and optimisation techniques. Engng. Anal. Bound. Elem. 35(8), 984-995.

20. Tafreshi, A. (2002) Shape design sensitivity analysis of 2D anisotropic structures using the boundary element method. Eng. Anal Bound Elem, 26(3), 237-251.

21. Tafreshi, A. (2005) Optimum shape design of composite structures using the boundary element method. AIAA J, 43(6), 1349-1359.

22. Tafreshi, A. (2009) Shape sensitivity analysis of composites in contact using the boundary element method. Engng. Anal Bound Elem, , 33(2), 215-224.

23. Tafreshi, A. (2006) Shape design sensitivity analysis with respect to the positioning of features in composite structures using the boundary element method. Engng. Anal. Bound. Elem, 30(1), 1-13.

24. Tafreshi A. (2015) Efficient evaluation of the $\mathrm{J}_{2}$-integral using the boundary element crack shape sensitivities. Theoretical and applied fracture mechanics, 76, 9-16.

25. Tafreshi, A. (2016) Computation of the $J_{k}$-integrals for bimaterial interface cracks using boundary element crack shape sensitivities. Theoretical and applied fracture mechanics, 82,77-87. 
26. Milne, I.; Ritchie, R.O., and Karihaloo, B. (Eds)(2003) Comprehensive structural integrity Vol.1-10. Elsevier 27.,B.M. Malyshev and R.L. Salganik (1965) . The strength of adhesive joints using the theory of fracture. Int. J. of Fract. Mech., 1, 114-128.

28. Gosz, M., Okyar, A.F. and Nair, S. (2003) A crack driving force criterion for the prediction of interface crack kinking in thin film composites. Interface Science, 11, 329-338.

29. Khandelwal, R. and Chadra Kishen, J.M. (2006) Complex variable method of computing Jk for bimaterial interface cracks. Engng. Fract. Mech, 73, 1568-1580.

30. Wang, S.S., Yau, J.F. and Corten, H.T. (1980) A mixed-mode crack analysis of anisotropic solids using conservation laws of elasticity. I.J. Fract. 16, 247-259.

31. Chu, S J and Hong, C S (1990) Application of the $J_{k}$ integral to mixed mode crack problems for anisotropic composite laminates. Eng. Fract. Mech., 35(6), pp1093-1103.

32. Beom, H.G. and Cui, C.B. and Jang, H.S. (2012) Dependence of stress intensity factors on elastic constants for cracks in an orthotropic bimaterial with a thin film. Int. J. Solids Struct., 49, 3461-3471.

33. Chow, W.T., Beom, H.G. and Atluti, S.N. (1995) Calculation of stress intensity factors for an interfacial crack between dissimilar anisotropic media, using a hybrid element method and the mutual integral. Comput. Mech., 15, 546-557.

34. Song, C., Tin-Loi, F. and Gao, W. (2010) Transient dynamic analysis of interface cracks in anisotropic bimaterials by the scaled boundary finiteelement method. Int. J. Solids Struct., 47, 978-989.

35. Ang, H.E., Torrance, J.E. and Tan, C.L. (1996) Boundary element analysis of orthotropic delamination specimens with interface cracks. Engng. Fract. Mech, 54(5), 601-615.

36. Ikeda, T., Nagai, M., Yamanaga, K. and Miyazaki, N. (2006) Stress intensity factor analyses of interface cracks between dissimilar anisotropic materials using the finite element method. Engng. Fract. Mech., 73, 20672079. 
37. Jun, L., Garcia-Sanchez, F., Wunsche, M., Zhang,C., Wang,Y-S and Saez, A. (2009) Dynamic analysis of interfacial crack problems in anisotropic bimaterials by a time-domain BEM. Engng. Fract. Mech., 76, 1996-2010

38. Lekhnitskii, S.G. (1963) Theory of elasticity of an anisotropic elastic body. Holden-Day, San Fransisco.

39. Eshelby, J.D, Read, W.T., Shockley, W. (1953) Anisotropic elasticity with applications to dislocation theory. Acta Metall., 1, 251-259.

40. Stroh, A.N. (1958) Dislocation and cracks in anisotropic elasticity. Philos.. Mag. 3, 625-646.

41. Dundors, J. (1969) Discussion: edge-bonded dissimilar orthogonal elastic wedges under normal and shear loading. J. Applied Mech., 36: 650-656.

42. Cherepanov, G.P. (1979) Mechanics of brittle fracture. McGraw-Hill, NewYork.

43. Gibson, R.F. (1994) Principles of composite material mechanics. McGrawHill, New York.

44. He, Z., Kotousov A. and Berto F. (2015) Effect of vertex singularities on stress intensities near plate free surfaces, Fatigue Fract. Engng Mater. Struct., 38: 860-869

45. Pook, L.P. (2013) A 50 year retrospective review of 3D effects at cracks and sharp notches, Fatigue Fract. Engng Mater. Struct., 36: 699-723

46. Lazzarin, P. and Zambardi, R. (2002) The equivalent strain energy density approach reformulated and applied to sharp V-shaped notches under localized and generalized plasticity. Fatigue Fract. Engng Mater. Struct., 25: 917-928

47. Lazzarin, P., Sonsino, C.M. and Zambardi, R. (2004) A notch stress intensity approach to assess the multiaxial fatigue strength of welded tube-to-flange joints subjected to combined loadings, Fatigue Fract. Engng Mater. Struct., 27, 127-140

48. Lazzarin, P., Livieri, P. and Zambardi, R. (2002) A J-integral based approach to predict the fatigue strength of components weakened by sharp V-shaped notches, Int. J. Comp. Appl. Techn., 15, 202-210 
49. Berto, F. and Lazzarin, P. (2007) Relationships between J-integral and strain energy evaluated in a finite volume surrounding the tip of sharp and blunt V-notches, Int. J. Solids Struct., 44, 4621-4645

50. Radaj, D. (2015) State of the art review on the local strain energy density concept and its relation to the J-integral and peak stress method, Fatigue Fract. Engng Mater. Struct., 38, 2-28

\section{Appendix A}

$$
\begin{array}{ll}
a_{11}=-\frac{S_{22}}{2} \operatorname{Im}\left(\frac{\mu_{1}+\mu_{2}}{\mu_{1} \mu_{2}}\right) & a_{22}=\frac{S_{11}}{2} \operatorname{Im}\left(\mu_{1}+\mu_{2}\right) \\
a_{12}=-\frac{S_{22}}{2} \operatorname{Im}\left(\frac{1}{\mu_{1} \mu_{2}}\right)+\frac{S_{11}}{2} \operatorname{Im}\left(\mu_{1} \mu_{2}\right) & b_{11}=\frac{1}{2} \operatorname{Im}\left(\omega_{11} \omega_{21}+\omega_{31} \omega_{41}\right) \\
b_{22}=\frac{1}{2} \operatorname{Im}\left(\omega_{12} \omega_{22}+\omega_{32} \omega_{42}\right) & b_{12}=\frac{1}{2} \operatorname{Im}\left(\omega_{11} \omega_{22}+\omega_{12} \omega_{21}+\omega_{31} \omega_{42}+\omega_{32} \omega_{41}\right)
\end{array}
$$

The parameters $\omega_{l m}(\mathrm{l}=1,4, \mathrm{~m}=1,2)$ are defined as

$$
\begin{aligned}
& \omega_{11}=\frac{\mu_{1} \mu_{2}}{\mu_{1}-\mu_{2}}\left(-\frac{\mu_{1}}{\sqrt{\mu_{1}}}+\frac{\mu_{2}}{\sqrt{\mu_{2}}}\right), \omega_{12}=\frac{1}{\mu_{1}-\mu_{2}}\left(-\frac{\mu_{1}^{2}}{\sqrt{\mu_{1}}}+\frac{\mu_{2}^{2}}{\sqrt{\mu_{2}}}\right) \\
& \omega_{21}=\frac{\mu_{1} \mu_{2}}{\mu_{1}-\mu_{2}}\left(-\frac{A_{11}}{\sqrt{\mu_{1}}}+\frac{A_{12}}{\sqrt{\mu_{2}}}\right), \omega_{22}=\frac{1}{\mu_{1}-\mu_{2}}\left(-\frac{A_{11} \mu_{1}}{\sqrt{\mu_{1}}}+\frac{A_{12} \mu_{2}}{\sqrt{\mu_{2}}}\right) \\
& \omega_{31}=\frac{\mu_{1} \mu_{2}}{\mu_{1}-\mu_{2}}\left(-\frac{1}{\sqrt{\mu_{1}}}-\frac{1}{\sqrt{\mu_{2}}}\right), \omega_{32}=\frac{1}{\mu_{1}-\mu_{2}}\left(\frac{\mu_{1}}{\sqrt{\mu_{1}}}-\frac{\mu_{2}}{\sqrt{\mu_{2}}}\right) \\
& \omega_{41}=\frac{\mu_{1} \mu_{2}}{\mu_{1}-\mu_{2}}\left(-\frac{A_{21}}{\sqrt{\mu_{1}}}+\frac{A_{22}}{\sqrt{\mu_{2}}}\right), \omega_{42}=\frac{1}{\mu_{1}-\mu_{2}}\left(-\frac{A_{21} \mu_{1}}{\sqrt{\mu_{1}}}+\frac{A_{22} \mu_{2}}{\sqrt{\mu_{2}}}\right)
\end{aligned}
$$




\section{Appendix B}

$$
z=r e^{i \theta} \quad d z=i z d \theta
$$

$\int_{0}^{\pi}\left(c_{1} z\right)^{-\frac{1}{2}+i \varepsilon}\left(c_{2} \bar{z}\right)^{-\frac{1}{2}+i \varepsilon} d z=\int_{0}^{\pi}\left(c_{1} z\right)^{-\frac{1}{2}-i \varepsilon}\left(c_{2} \bar{z}\right)^{-\frac{1}{2}+i \varepsilon} d z=0$.

$\int_{0}^{\pi}\left(c_{1} z\right)^{-\frac{1}{2}+i \varepsilon}\left(c_{2} \bar{z}\right)^{-\frac{1}{2}-i \varepsilon} d z=\int_{0}^{\pi}\left(c_{1} z\right)^{-\frac{1}{2}-i \varepsilon}\left(c_{2} \bar{z}\right)^{-\frac{1}{2}-i \varepsilon} d z=0$.

$\int_{-\pi}^{0}\left(c_{1} z\right)^{-\frac{1}{2}+i \varepsilon}\left(c_{2} \bar{z}\right)^{-\frac{1}{2}+i \varepsilon} d z=\int_{-\pi}^{0}\left(c_{1} z\right)^{-\frac{1}{2}-i \varepsilon}\left(c_{2} \bar{z}\right)^{-\frac{1}{2}+i \varepsilon} d z=0$.

$\int_{-\pi}^{0}\left(c_{1} z\right)^{-\frac{1}{2}+i \varepsilon}\left(c_{2} \bar{z}\right)^{-\frac{1}{2}-i \varepsilon} d z=\int_{-\pi}^{0}\left(c_{1} z\right)^{-\frac{1}{2}-i \varepsilon}\left(c_{2} \bar{z}\right)^{-\frac{1}{2}-i \varepsilon} d z=0$.

$\int_{0}^{\pi} z^{-1} d z=\int_{-\pi}^{0} z^{-1} d z=i \pi$

$\int_{0}^{\pi} c^{2 i \varepsilon} z^{2 i \varepsilon-1} d z=\frac{i(c r)^{2 i \varepsilon}\left|\beta_{0}\right|}{\varepsilon\left(1+\left|\beta_{0}\right|\right)} \quad \int_{-\pi}^{0} c^{2 i \varepsilon} z^{2 i \varepsilon-1} d z=\frac{i(c r)^{2 i \varepsilon}\left|\beta_{0}\right|}{\varepsilon\left(1-\left|\beta_{0}\right|\right)}$

$\int_{0}^{\pi} c^{-2 i \varepsilon} z^{-2 i \varepsilon-1} d z=\frac{i(c r)^{-2 i \varepsilon}\left|\beta_{0}\right|}{\varepsilon\left(1-\left|\beta_{0}\right|\right)} \quad \int_{-\pi}^{0} c^{-2 i \varepsilon} z^{-2 i \varepsilon-1} d z=\frac{i(c r)^{-2 i \varepsilon}\left|\beta_{0}\right|}{\varepsilon\left(1+\left|\beta_{0}\right|\right)}$

where $(c r)^{2 i \Omega \varepsilon}=\cos 2 \varepsilon \operatorname{Ln} c r+\Omega i \sin 2 \varepsilon \operatorname{Ln} c r$

Here $c, c_{1}$ and $c_{2}$ are constant real parameters. $\Omega$ is equal to +1 and -1 for materials 1 and 2 , respectively.

\section{Appendix C}

Based on the definition of complex functions $\phi(z)$ and $\psi(z)$ given by equation (26), the following integrals are determined.

$$
\begin{aligned}
& \int_{(n)}^{(n)} \psi^{2} d z=\frac{2 i\left|\beta_{0}\right|}{\varepsilon} \cos 2 \varepsilon \operatorname{Ln} r-\frac{2 \Omega \beta_{0}^{2}}{\varepsilon} \sin 2 \varepsilon \operatorname{Ln} r+2 i \pi\left(1-\beta_{0}^{2}\right) \\
& \int_{(n)}^{(n)} \phi^{2} d z=\frac{2 i}{\varepsilon\left|\beta_{0}\right|} \cos 2 \varepsilon \operatorname{Ln} r-\frac{2 \Omega}{\varepsilon} \sin 2 \varepsilon \operatorname{Ln} r-\frac{2 i \pi\left(1-\beta_{0}^{2}\right)}{\beta_{0}^{2}} \\
& \int_{(n)}^{(n)(n)} \phi \psi d z=\frac{2 i \Omega\left|\beta_{0}\right|}{\varepsilon} \cos 2 \varepsilon \operatorname{Ln}(r)-\frac{2}{\varepsilon} \sin 2 \varepsilon \operatorname{Ln}(r)
\end{aligned}
$$


where $\mathrm{n}$ is the material number. It is assumed that for material $1,0 \leq \theta \leq \pi$, and for material $2,-\pi \leq \theta \leq 0$.

\section{Appendix D}

According to the definition of $z_{1}$ and $z_{2}$ given by equation 41 , the complex functions $D_{1}\left(z_{j}\right), D_{2}\left(z_{j}\right), \psi\left(z_{j}\right), \phi\left(z_{j}\right), d_{1 j}(z), d_{2 j}(z), \psi_{j}(z), \phi_{j}(z)$ for each material are defined as

$$
\begin{aligned}
& D_{1}^{(n)}\left(z_{j}\right)=\left(-i \mu_{j}\right)^{-\frac{1}{2}} d_{1 j}^{(n)}(z) \\
& D_{2}^{(n)}\left(z_{j}\right)=\left(-i \mu_{j}\right)^{-\frac{1}{2}} d_{2 j}^{(n)}(z) \\
& { }_{(n)}^{(n)}\left(z_{j}\right)=\left(-i \mu_{j}\right)^{-\frac{1}{2}} \psi_{j}^{(n)}(z) \\
& \phi\left(z_{j}\right)=\left(-i \mu_{j}\right)^{-\frac{1}{2} \stackrel{(n)}{\phi}_{j}(z)}
\end{aligned}
$$

where

$$
\begin{aligned}
& d_{1 j}^{(n)}(z)=\left[\begin{array}{l}
(n) \\
p_{j}^{i \varepsilon} z^{i b-\frac{1}{2}}+p_{j}^{-i \varepsilon} z^{-i s}
\end{array}\right] \\
& d_{2 j}^{(n)}(z)=\left[\begin{array}{l}
(n) \\
p_{j}^{i \varepsilon} z^{i k-\frac{1}{2}}-p_{j}^{-i \varepsilon} z^{-i s-\frac{1}{2}}
\end{array}\right] \\
& \stackrel{(n)}{\psi_{j}}(z)=\left[d_{1 j}^{(n)}(z)+\Omega\left|\beta_{0}\right| d_{2 j}^{(n)}(z)\right] \\
& \stackrel{(n)}{\phi}_{j}(z)=\left[\Omega d_{j 1}^{(n)}(z)+\frac{d_{2 j}^{(n)}(z)}{\left|\beta_{0}\right|}\right]
\end{aligned}
$$




\section{Appendix E}

$$
\begin{aligned}
& \omega_{\varepsilon}=q^{T} . P^{T} . B^{T} . A . P . q=\left[\begin{array}{ll}
\omega_{\varepsilon_{11}} & \omega_{\varepsilon_{12}} \\
\omega_{\varepsilon_{21}} & \omega_{\varepsilon_{22}}
\end{array}\right]= \\
& {\left[\begin{array}{cc}
\frac{S_{22}-S_{11} \mu_{1}^{4}}{\left(\mu_{2}-\mu_{1}\right)^{2}} & \frac{\mu_{1} S_{22}+S_{12} \mu_{1} \mu_{2}\left(\mu_{2}-\mu_{1}\right)-S_{11} \mu_{1}^{2} \mu_{2}^{3}}{\sqrt{\mu_{1} \mu_{2}}\left(\mu_{2}-\mu_{1}\right)^{2}} \\
\frac{\mu_{2} S_{22}-S_{12} \mu_{1} \mu_{2}\left(\mu_{2}-\mu_{1}\right)-S_{11} \mu_{1}^{3} \mu_{2}^{2}}{\sqrt{\mu_{1} \mu_{2}}\left(\mu_{2}-\mu_{1}\right)^{2}} & \frac{S_{22}-S_{11} \mu_{2}^{4}}{\left(\mu_{2}-\mu_{1}\right)^{2}}
\end{array}\right]}
\end{aligned}
$$

where

$$
\omega_{\varepsilon_{12}}+\omega_{\varepsilon_{21}}=\frac{\left(\mu_{1}+\mu_{2}\right)\left(S_{22}-S_{11} \mu_{1}^{2} \mu_{2}^{2}\right)}{\sqrt{\mu_{1} \mu_{2}}\left(\mu_{2}-\mu_{1}\right)^{2}}
$$

Since $\mu_{1} \mu_{2}=\sqrt{\frac{S_{11}}{S_{22}}}$, therefore, $\omega_{\varepsilon_{12}}+\omega_{\varepsilon_{21}}=0$.

\section{Appendix F}

$$
\begin{aligned}
& \int_{(n)}^{(n)} M_{11}^{2} d z=\int_{(n)}\left[\begin{array}{l}
(n) \\
\psi_{1}^{2}
\end{array}+\left(\begin{array}{l}
(n) \\
p_{2}
\end{array}\right)^{2} \beta_{21}^{2} \stackrel{(n)}{\phi_{1}^{2}}-2 \stackrel{(n)}{p_{2}} \beta_{21} \stackrel{(n)}{\phi_{1}} \psi_{1} \psi_{1}\right] d z \\
& \int_{(n)}^{(n)} M_{21}^{2} d z=\int_{(n)}\left[\stackrel{(n)}{\psi_{2}^{2}}+\left(\begin{array}{c}
(n) \\
p_{1}
\end{array}\right)^{2} \beta_{21}^{2} \stackrel{(n)}{\phi_{2}^{2}}-2 \stackrel{(n)}{p_{1}} \beta_{21} \stackrel{(n)(n)}{\phi_{2} \psi_{2}}\right] d z \\
& \int_{(n)} M_{12}^{(n)} d z=-\int_{(n)}\left[\left({ }_{(n)}^{(n)}{ }^{2}\right)^{2} \stackrel{(n)}{\psi_{1}^{2}}+\beta_{12}^{2} \stackrel{(n)}{\phi_{1}^{2}}+2 \stackrel{(n)}{p_{2}} \beta_{12} \stackrel{(n)(n)}{\phi_{1} \psi_{1}}\right] d z \\
& \int_{(n)}^{(n)} M_{22}^{2} d z=-\int_{(n)}\left[\left({ }_{(n)}^{(n)}\right)_{1}^{2}{ }^{(n)} \psi_{2}^{2}+\beta_{12}^{2} \stackrel{(n)}{\phi_{2}^{2}}+2 \stackrel{(n)}{p_{1}} \beta_{12} \stackrel{(n)(n)}{\phi_{2} \psi_{2}}\right] d z \\
& \int_{(n)}^{(n)} \psi_{j}^{2} d z=\frac{2 i \beta_{0}}{\varepsilon} \cos 2 \varepsilon \operatorname{Ln}\left(\stackrel{(n)}{p_{j}} r\right)-\frac{2 \Omega \beta_{0}^{2}}{\varepsilon} \sin 2 \varepsilon \operatorname{Ln}\left(\stackrel{(n)}{p_{j}} r\right)+2 i \pi\left(1-\beta_{0}^{2}\right) \\
& \int_{(n)}^{(n)} \phi_{j}^{2} d z=\frac{2 i}{\varepsilon \beta_{0}} \cos 2 \varepsilon \operatorname{Ln}\left(\stackrel{(n)}{p_{j}} r\right)-\frac{2 \Omega}{\varepsilon} \sin 2 \varepsilon \operatorname{Ln}\left(\stackrel{(n)}{p_{j}} r\right)-\frac{2 i \pi\left(1-\beta_{0}^{2}\right)}{\beta_{0}^{2}}
\end{aligned}
$$

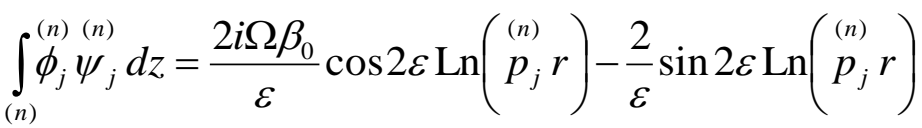


Table 1 Typical values of lamina engineering constants for several composites $^{43}$

\begin{tabular}{|c|c|c|c|c|c|c|c|c|c|}
\hline & Case & & $\begin{array}{c}\mathrm{E}_{1} \\
(\mathrm{GPa})\end{array}$ & $\begin{array}{c}\mathrm{E}_{2} \\
(\mathrm{GPa})\end{array}$ & $\begin{array}{c}\mathrm{G}_{12} \\
(\mathrm{GPa})\end{array}$ & $v_{12}$ & $\mu_{1}$ & $\mu_{2}$ & $\varepsilon$ \\
\hline $\begin{array}{l}\text { Material- } \\
1\end{array}$ & $\mathrm{~N} / \mathrm{A}$ & $\begin{array}{l}\text { p-100/ERL } 1962 \\
\text { pitch Graphite/epoxy }\end{array}$ & 468.9 & 6.2 & 5.58 & 0.31 & 9.082i & $0.957 i$ & $\mathrm{~N} / \mathrm{A}$ \\
\hline \multirow{7}{*}{$\begin{array}{l}\text { Material- } \\
2\end{array}$} & 1 & $\begin{array}{l}\text { T300/934 } \\
\text { Graphite/epoxy }\end{array}$ & 131 & 10.3 & 6.9 & 0.22 & $4.222 \mathrm{i}$ & $0.844 \mathrm{i}$ & 0.0174 \\
\hline & 2 & $\begin{array}{l}\text { AS/3501 } \\
\text { Graphite/epoxy }\end{array}$ & 138 & 9 & 6.9 & 0.3 & $4.309 i$ & $0.908 \mathrm{i}$ & 0.0188 \\
\hline & 3 & $\begin{array}{l}\text { Kevlar 49/934 } \\
\text { aramid/epoxy }\end{array}$ & 75.8 & 5.5 & 2.3 & 0.34 & $5.643 \mathrm{i}$ & $0.657 i$ & 0.0374 \\
\hline & 4 & $\begin{array}{l}\text { Scotchply } 1002 \\
\text { E-glass/epoxy }\end{array}$ & 38.6 & 8.27 & 4.14 & 0.26 & $2.870 \mathrm{i}$ & $0.752 \mathrm{i}$ & 0.0474 \\
\hline & 5 & $\begin{array}{l}\text { Boron/5505 } \\
\text { boron/epoxy }\end{array}$ & 204 & 18.5 & 5.59 & 0.23 & $5.977 i$ & $0.555 i$ & 0.0069 \\
\hline & 6 & $\begin{array}{l}\text { Spectra 900/826 } \\
\text { Polyethylene/epoxy }\end{array}$ & 30.7 & 3.52 & 1.45 & 0.32 & $4.483 \mathrm{i}$ & $0.658 \mathrm{i}$ & 0.0609 \\
\hline & 7 & $\begin{array}{l}\text { E-glass/470-36 } \\
\text { E-glass/vinylester }\end{array}$ & 24.4 & 6.87 & 2.89 & 0.32 & $2.705 \mathrm{i}$ & $0.696 \mathrm{i}$ & 0.0553 \\
\hline
\end{tabular}


Table 2 Stress intensity factors for each bimaterial plate with a central crack

\begin{tabular}{|c|c|c|}
\hline Bimaterial No. & $\mathrm{K}_{1}(M P a \sqrt{m m})$ & $\mathrm{K}_{2}(M P a \sqrt{m m})$ \\
\hline 1 & $5.607 \mathrm{E}+02$ & -22.694 \\
\hline 2 & $5.607 \mathrm{E}+02$ & -25.012 \\
\hline 3 & $5.616 \mathrm{E}+02$ & -45.707 \\
\hline 4 & $5.623 \mathrm{E}+02$ & -49.166 \\
\hline 5 & $5.605 \mathrm{E}+02$ & -9.096 \\
\hline 6 & $5.635 \mathrm{E}+02$ & -65.705 \\
\hline 7 & $5.630 \mathrm{E}+02$ & -52.296 \\
\hline
\end{tabular}




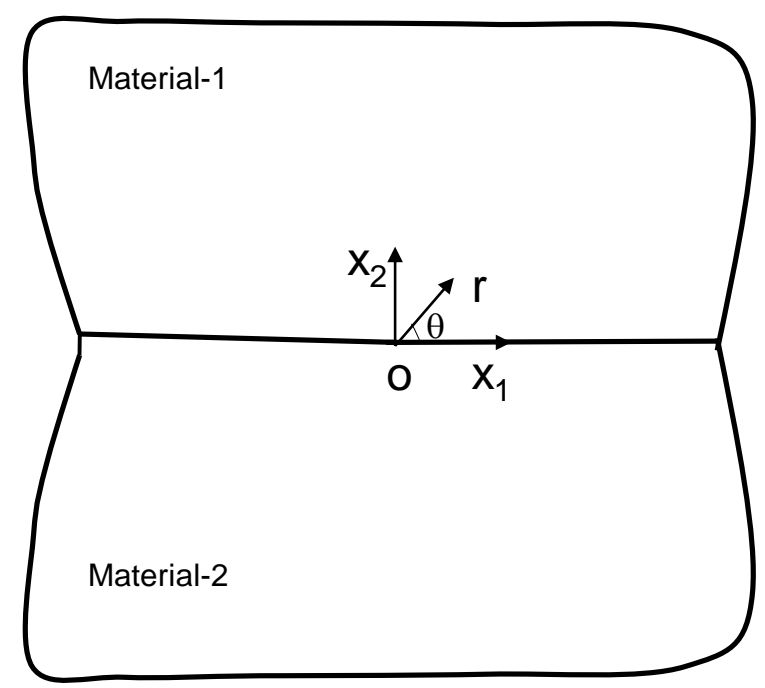

Figure 1a A bimaterial structure with an intact interface

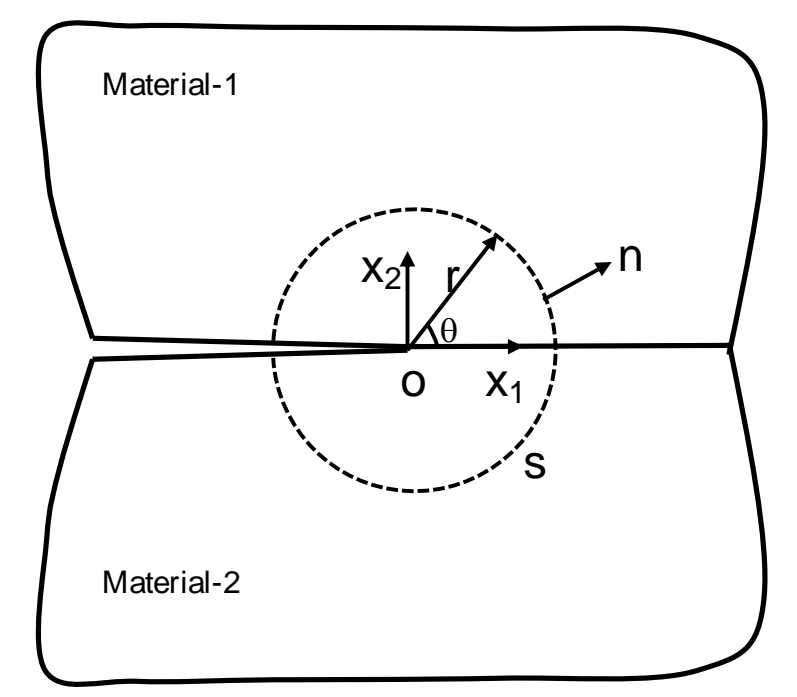

Figure 1b A bimaterial structure with an interface crack 


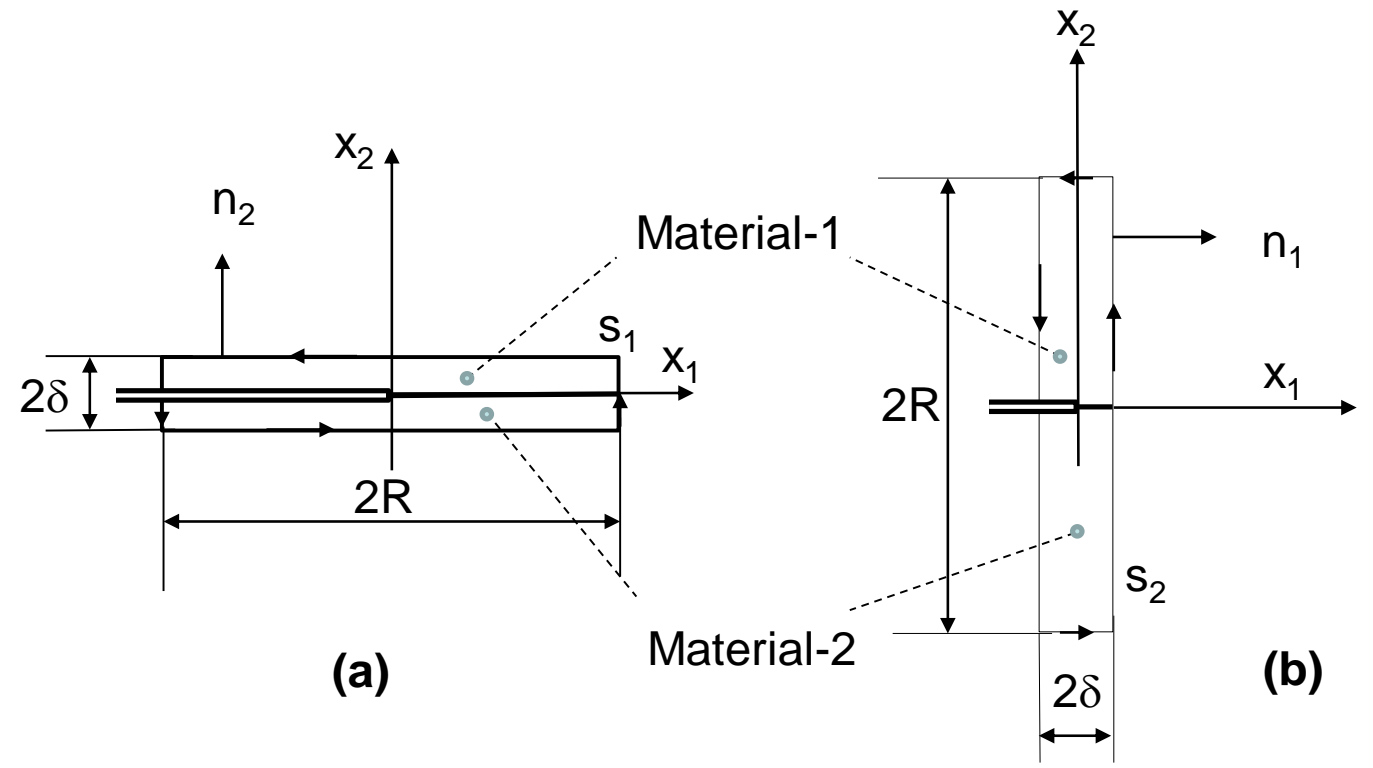

Figure 2 Narrow rectangular contours for calculation of the $J_{1}$ and $J_{2}$-integrals 


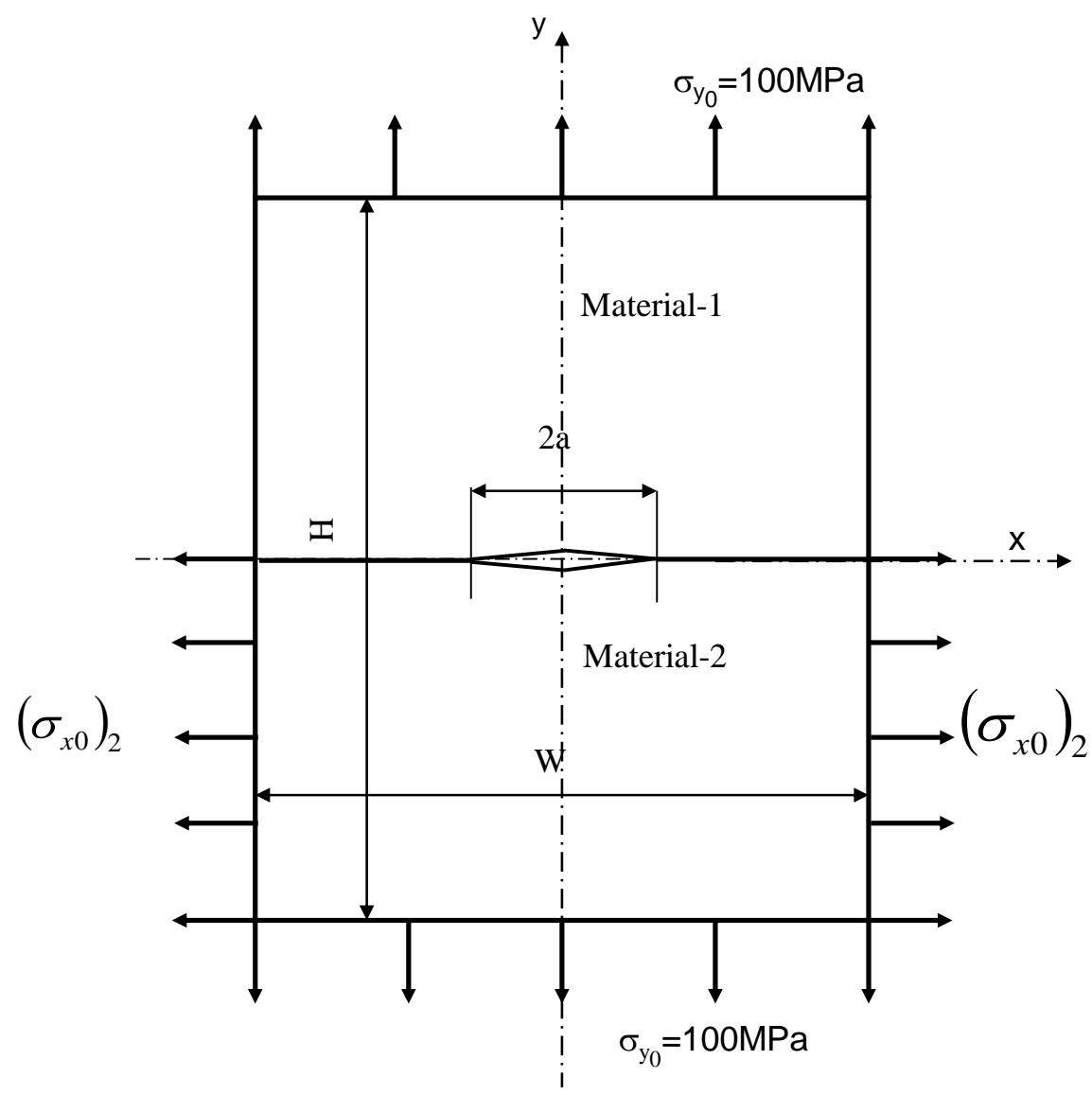

Figure 3 A bimaterial plate with an interface crack subject to tension 
Fig. 4 Variation of the analytical values of $-J_{2}$-integral with respect to $r / a$ for the plate with a central crack subject to tension for different bimaterial combinations

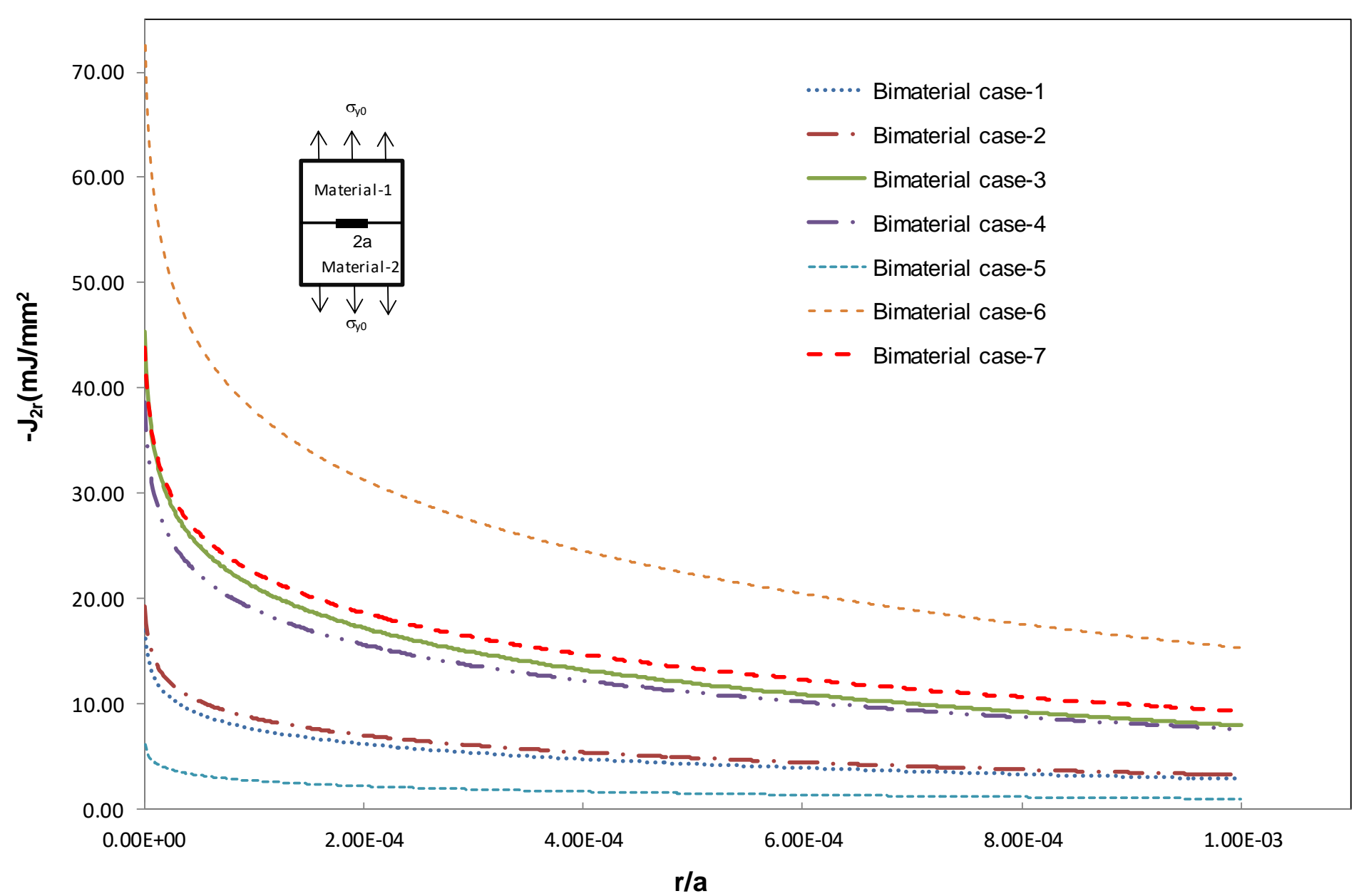




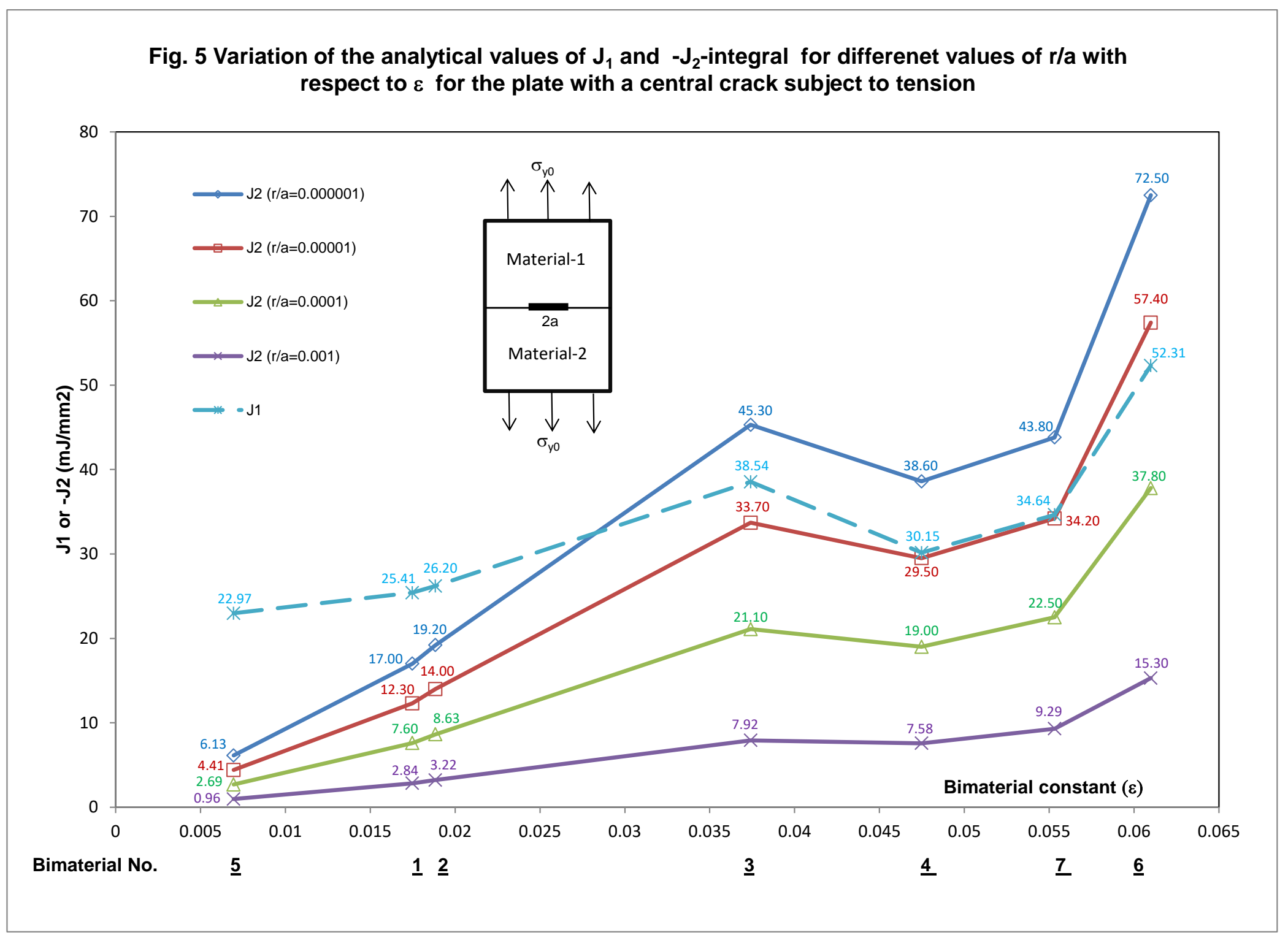

